\title{
Nano- and Microstructured Copper/Copper Oxide Composites on Laser-Induced Carbon for Enzyme-Free Glucose Sensors
}

\author{
Emil R. Mamleyev, Peter G. Weidler, Alexei Nefedov, Dorothée Vinga Szabó, Monsur Islam, \\ Dario Mager, and Jan G. Korvink*
}

Cite This: ACS Appl. Nano Mater. 2021, 4, 13747-13760

Read Online

ACCESS

Lلll Metrics \& More

回国 Article Recommendations

(s) Supporting Information

ABSTRACT: Low-cost enzyme-free glucose sensors with partial flexibility adaptable for wearable Internet of Things devices that can be envisioned as personalized point-of-care devices were produced by electroplating copper on locally carbonized flexible meta-polyaramid (Nomex) sheets using laser radiation. Freestanding films were annealed in nitrogen and nitrogen/air working environments, leading to the formation of $\mathrm{Cu}$ microspheroids and $\mathrm{CuO}$ urchins dispersed on the substrate film. The aggregation mechanism, crystallographic properties, surface chemistry, and electrochemical properties of the films were studied using scanning electron microscopy, X-ray diffractometry, transmission electron microscopy, X-ray photoelectron spectroscopy, and cyclic voltammetry. $\mathrm{Cu}$ microspheroids and $\mathrm{CuO}$ urchins attained activity for glucose detection and showed improvement of amperometric sensitivity to 0.25 and $0.32 \mathrm{~mA} \mathrm{~cm}^{-2} \mathrm{mM}^{-1}$, respectively.
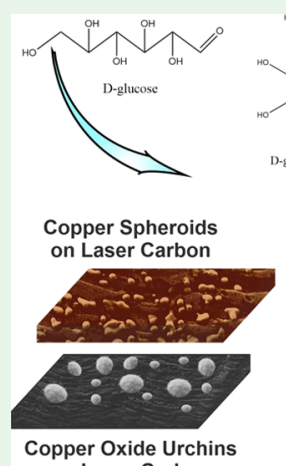

Copper Oxide Urchin
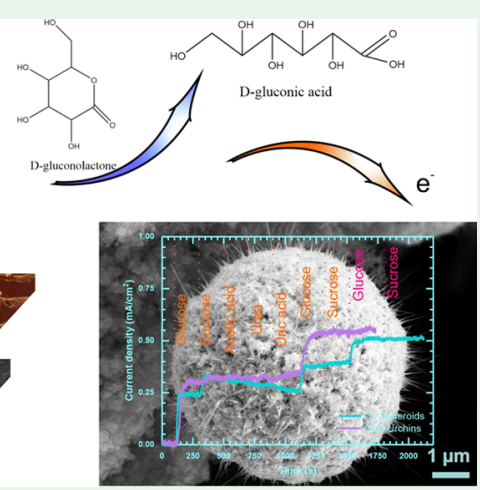

The $\mathrm{CuO}$ urchin film retained its chemical composition after amperometric testing, and, by rinsing, allowed multiple repetitions with reproducible results. This study opens the possibility for the fabrication of durable composite biosensors with tailored shape, capable of implementation in flexible carriers, and microfluidic systems.

KEYWORDS: polyaramid, laser-induced carbonization, copper, copper oxide urchins, glucose sensing

\section{INTRODUCTION}

Glucose detection is essential in the healthcare monitoring of people suffering from diabetes mellitus. Increased levels of blood glucose directly relate to the risks in the development of cardiac arrests, ${ }^{1}$ renal failure, ${ }^{2}$ blindness, ${ }^{3}$ and cerebral, and neuronal damage. ${ }^{4}$ Globally, the number of people diagnosed with diabetes mellitus is currently estimated at about 500 million by the International Diabetes Federation, ${ }^{5}$ and the number is steadily rising, which lays a huge burden on the healthcare system. Thus, direct monitoring of glucose concentration in blood and sweat is essential for timely assistance and prevention. ${ }^{5,6} \mathrm{~A}$ new generation of low-cost point-of-care sensors addresses this problem and provides direct analysis of the glucose concentration. ${ }^{7,8}$

Traditional glucose sensors are mostly of enzymatic nature, where a glucose oxidase enzyme is immobilized on a sensing material. ${ }^{9,10}$ The sensing mechanism of such sensors relies on the oxidation of glucose to D-gluconolactone, the subsequent generation of hydrogen peroxide, and further on to gluconic acid. ${ }^{11-13}$ However, the extraction of the enzymes from fungus, such as industrially accepted Aspergillus niger, ${ }^{9,12}$ is expensive. Furthermore, long-term stability and storage of the enzymatic sensors are of major concern. ${ }^{11}$ Therefore, in recent years, significant attention has been paid to enzyme-free biosensors, where several noble metals, ${ }^{14-17}$ metal nanoparticles, ${ }^{8,18-20}$ and transition-metal oxides ${ }^{11,21-23}$ have been exploited as the electroactive material for glucose sensing. The use of these materials for biosensing majorly relies on the fabrication of composite electrodes, typically with a carbon-based material such as graphene, ${ }^{24,25}$ carbon nanotubes, ${ }^{26,27}$ and glassy carbon, ${ }^{28-30}$ which further reinforces the essential biocompatibility of the sensing material. Among various electroactive materials, copper and copper oxide exhibit a significant electrocatalytic activity for glucose oxidation, due to its lower overpotential induced by an electron transfer. ${ }^{11,28,31}$ Moreover, copper oxide nanowires allow an improvement in the sensitivity of detection due to their higher surface-to-volume ratio. ${ }^{19,32,33}$ Notably, the surface area can be further increased by the growth of nanowires on the spheroids, leading to an urchin-like morphology. Because of their superior morphologies, urchin materials have demonstrated significantly higher sensitivity for glucose detection compared to other copperbased materials. ${ }^{34}$ However, the $\mathrm{CuO}$ urchin-based glucose

Received: September 28, 2021

Accepted: November 22, 2021

Published: December 6, 2021

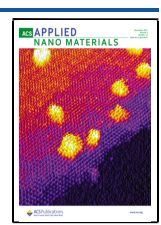


sensors reported to date were on rigid substrates, used for the detection of $\mathrm{H}_{2} \mathrm{O}_{2}{ }^{35}$ and humidity. ${ }^{36}$ Even though the fabrication of flexible biosensors has been reported using bulk copper oxide ${ }^{37}$ and its nanowire variant, ${ }^{11,25,28,32,38}$ urchin-like morphologies are still unexplored for flexible sensor devices. Furthermore, current state of the art for the synthesis of urchin morphologies only includes the hydrothermal method and some chemical methods. ${ }^{35,36}$ Here, we focus on the fabrication of a $\mathrm{CuO}$ urchin-based flexible glucose sensor, where the urchin structures are achieved solely by thermal annealing, together with a straightforward variation of the working environment.

As a promising method for the development of a new generation of economic point-of-care devices, laser-induced carbonization (LIC) has manifested itself as a rapid and lowcost fabrication method. ${ }^{39,40}$ The fabrication process of LIC utilizes localized laser irradiation for immediate conversion of the polymer substrate to a conductive film. This process works for a wide range of possible wavelengths. ${ }^{39-41}$ The laser carbon (LC) is induced by a combination of photochemical and photothermal mechanisms, ${ }^{39,42}$ forming conductive, highly porous, highly graphitized, carbon-rich films, which are embedded directly in the polymer precursor. ${ }^{40} \mathrm{~A}$ number of high-temperature thermosets can be used as precursors for LIC, including polyaramid Nomex. ${ }^{43,44}$ Laser carbon derived from Nomex exhibits a superior conductivity $\left(\sim 45 \mathrm{~S} \mathrm{~cm}^{-1}\right)$ compared to other precursors converted with $10.6 \mu \mathrm{m}$ wavelength laser radiation. ${ }^{44}$ LIC has revealed itself as a suitable process for the fabrication of chemical sensors, ${ }^{45-47}$ and biological sensors, ${ }^{48,49}$ due to its high surface activity. These advantages of LIC allow accurate detection with a low concentration of such biological metabolites as urea, ${ }^{48}$ dopamine, ${ }^{50} \mathrm{H}_{2} \mathrm{O}_{2}$, ${ }^{51}$ thrombin, ${ }^{52}$ and glucose. ${ }^{8,20,53}$ The substrate was successfully employed in glucose sensing, with enzymatic anchoring via an intermediate chitosan layer ${ }^{8}$ and via a composite deposition of metal nanoparticles. ${ }^{20,53}$

Here, we report on the fabrication of copper microspheres (Cu-MS) and copper oxide urchin ( $\mathrm{CuO}-\mathrm{U})$-based flexible glucose biosensors. The sensor electrodes are fabricated by laser-induced carbonization of flexible Nomex sheets, followed by electroplating of copper, high-temperature annealing, and preferential oxidation toward obtaining either $\mathrm{Cu}-\mathrm{MS}$ or $\mathrm{CuO}$ U. We study the effect of different processing parameters to understand the formation of both materials. We characterize the material properties using scanning electron microscopy (SEM), X-ray diffractometry (XRD), transmission electron microscopy (TEM), and X-ray photoelectron spectroscopy (XPS). We then present the electrochemical performances of these materials with potentiostatic cyclic voltammetry (CV) and use them for the amperometric glucose detection with real-time amperometry. We end with a discussion on the perspective of our electrode materials in point-of-care applications.

\section{MATERIALS AND METHODS}

2.1. Fabrication. The fabrication of the electroplated film on laser carbon was derived from Mamleyev et al. ${ }^{44}$ Poly(1,3-phenylene isophthalamide), commercially known as Nomex Type 410 insulation paper (DuPont; supplied by RS Components), of thickness $130 \pm 13$ $\mu \mathrm{m}$, was rinsed with isopropanol and dried for $10 \mathrm{~min}$ naturally. The films were fixed on glass slides with acrylic adhesive films (3M$467 \mathrm{MP}$ ) to prevent the films from warping during fabrication. LIC on Nomex was carried out with a $\mathrm{CO}_{2}$ laser (ULS Versa Laser 3.50, wavelength: $10.6 \mu \mathrm{m}$, lens $2.0 \mathrm{in}$., beam diameter $120 \mu \mathrm{m}$ at focus).
The fabrication was performed at a $3 \mathrm{~W}$ power, a $13 \mathrm{~cm} \mathrm{~s}^{-1}$ scanning speed, and a focal distance of $2.5 \mathrm{~mm}$. The pulse throughput was controlled by pulses per inch (PPI) and was set to 1000 along and perpendicular to the rasterization direction. During consecutive passes, the perpendicular PPI was reduced to 750 , and during the third pass, the speed was increased to $32 \mathrm{~cm} \mathrm{~s}^{-1}$. The supporting electrode for bent amperometric tests was fabricated using only two passes with 750 PPI and scan speeds of 13 and $32 \mathrm{~cm} \mathrm{~s}^{-1}$, which imparted flexibility to the carbonized films.

The copper electroplating was conducted in a custom-built electrolyte bath system (Cuprostar LP-1, Enthone-OMIGmbH) with $\mathrm{Cu}_{2} \mathrm{SO}_{4}(2 \mathrm{M}), \mathrm{H}_{2} \mathrm{SO}_{4}\left(7 \times 10^{-4} \mathrm{M}\right)$, and $\mathrm{HCl}\left(9 \times 10^{-6}\right.$ $\mathrm{M})$, following the manufacturer's specification for promoter additives. The bath was constantly stirred by an electric pump. A direct current of $30 \mathrm{~mA}$ was applied during the plating, and the deposition was performed for $600 \mathrm{~s}$. The electrode exposed to the electrolyte had a square shape with a $15 \mathrm{~mm}$ side length. The supporting electrode for bend tests was electroplated under the same current density. However, the plating time was increased to $3000 \mathrm{~s}$ due to the enlargement of the total area to $3.5 \mathrm{~cm}^{2}$ and an increase in resistance for carbon films prepared during the double laser passes.

The annealing was performed in a horizontal tube furnace (Carbolite Gero FHA 13) under a constant nitrogen flow $(\sim 0.8 \mathrm{~L}$ $\min ^{-1}$ ) for $1 \mathrm{~h}$, with a heating rate of $5{ }^{\circ} \mathrm{C} \mathrm{min}^{-1}$. To investigate the phenomenon of folding into spheroids, annealing was conducted at $800,900,1000$, and $1100{ }^{\circ} \mathrm{C}$, followed by natural cooling under $\mathrm{N}_{2}$ flow. For the growth of the $\mathrm{CuO}-\mathrm{U}$, we introduced air after $450{ }^{\circ} \mathrm{C}$ during the cooling step, following a specific regime for nanowire growth. ${ }^{54,55}$ Both types of the annealed samples fabricated at $1000{ }^{\circ} \mathrm{C}$ were selected for the glucose sensing and used for the amperometric studies.

2.2. Characterization. The surface morphology of each film was studied with a Carl Zeiss AG-SUPRA 60VP SEM equipped with a Bruker X-FLASH 5010 energy-dispersive X-ray (EDX) spectroscopy detector. XRD was conducted on a Bruker D8 Advance diffractometer in a $\theta-\theta$ geometry using $\mathrm{Cu} \mathrm{K} \alpha_{1,2}$ radiation. Bragg's formula was used for the determination of the interplane distances. Rietveld refinement was employed for the determination of the crystallite sizes and the internal stresses. ${ }^{56}$ TEM was carried out on a Thermo Fisher Scientific Themis 300 operated at $300 \mathrm{kV}$, with selected area electron diffraction (SAED) patterns collected at a camera length of $600 \mathrm{~mm}$ on a bottom-mounted Ceta $16 \mathrm{M}$ camera from studied specimens. Diffraction patterns were evaluated using the "PASAD"-plugin ${ }^{57}$ of the Gatan Digital Micrograph software. Laser carbon and CuO-U films were dispersed in ethanol and ultrasonicated for $1 \mathrm{~h}$, and then deposited on Quantifoil Holey Carbon Film supports with circular holes, type R1.2/1.3 + $2 \mathrm{~nm}$ additional continuous C layer on Au grid with 200 mesh.

XPS was performed using an $\mathrm{Al} \mathrm{K} \alpha$ radiation source $(E=1486.6$ $\mathrm{eV}$ ), and the spectra were collected with the hemispherical energy analyzer RG Scienta 4000. The survey and individual spectra were collected with 1 and $0.05 \mathrm{eV}$ increments, respectively. The spectra were analyzed using the CasaXPS software; all spectra were fit with a Gaussian-Lorentzian function and a Shirley background, excluding $\mathrm{Cu} 2 \mathrm{p}$ spectra, which were fit using a spline Tougaard background. The built-up charge accumulation resulted in the shift of the binding energy in all spectra, which was corrected by adjusting to the center adventitious carbon centered at $284.6 \mathrm{eV}$.

CV was performed on a modular AutoLab PGSTAT128N potentiostat/galvanostat equipped with NOVA software. The measurements were carried out in a three-electrode system: a working electrode, a platinum counter electrode, and a $\mathrm{Ag} / \mathrm{AgCl}$ reference electrode immersed in $1 \mathrm{M} \mathrm{KCl}$ solution. All experiments were conducted under constant stirring at $300 \mathrm{rpm}$. The procedure was carried out in $100 \mathrm{mM} \mathrm{NaOH}$ electrolyte, with the presence and absence of a $1 \mathrm{mM}$ glucose solution, within a potential range between -0.8 and $0.8 \mathrm{~V}$ for the determination of the characteristic redox potentials, and between 0 and $0.8 \mathrm{~V}$ to study only the oxidation behavior. The selected electrolyte provided a charge transfer during the glucose sensing and showed some influence of the concentration 


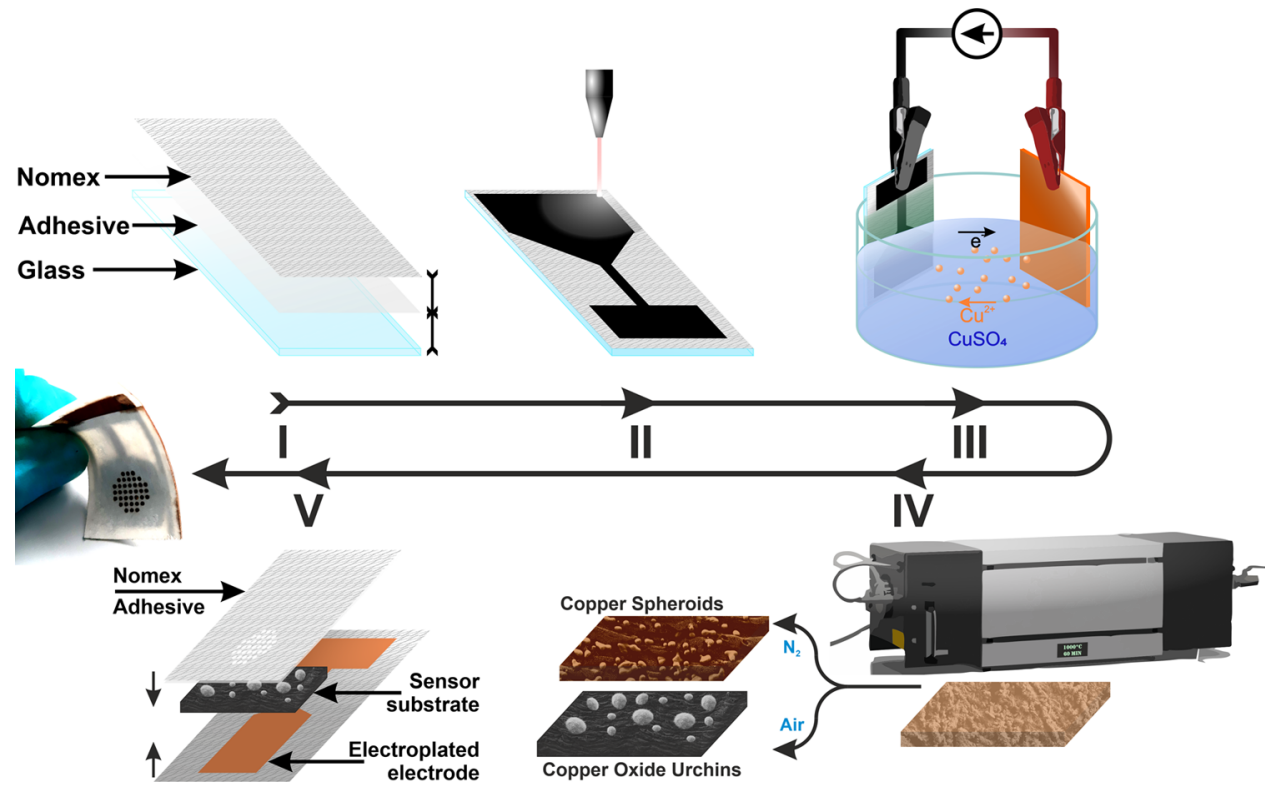

Figure 1. Schematic representation of the process flow. (I) Nomex paper attached to a glass slide; (II) fabricated electrode patterned with IR laser; (III) electrode electroplated with $\mathrm{Cu}$; (IV) detached substrate annealed in nitrogen (for $\mathrm{Cu}-\mathrm{MS}$ ) and nitrogen/air (for CuO-U) working environments; and (V) $\mathrm{CuO}-\mathrm{U}$ film attached to the plated contact pad and tested bent multiple times.

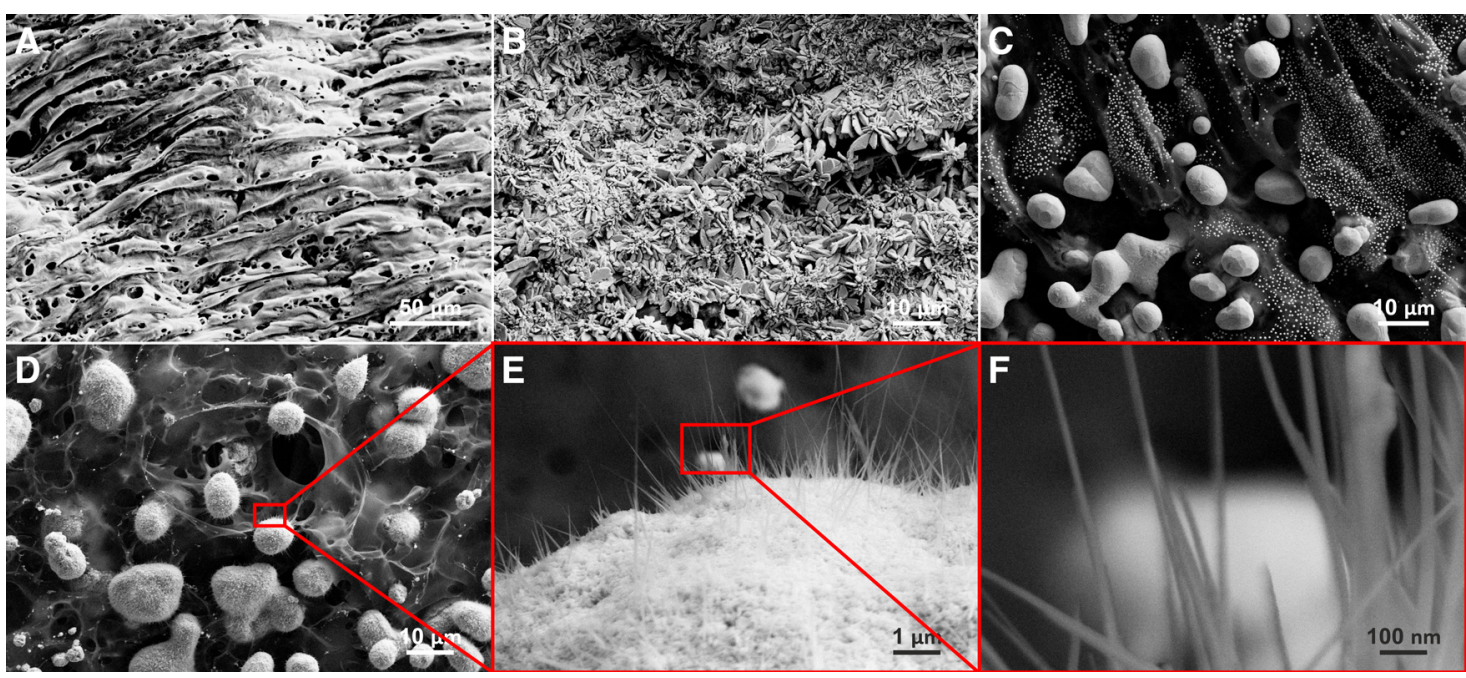

Figure 2. SEM images of (A) an initial laser carbon film, (B) a copper plated on laser carbon, and composites (C) $\mathrm{Cu}-\mathrm{MS}$ and (D) CuO-U, (E, F) with a magnification on the copper nanowires.

of $\mathrm{NaOH}$ in the amperometric signal, but without any significant contribution above $100 \mathrm{mM}$, which was chosen as a standard concentration for the solution for the electrochemical tests. ${ }^{11}$

Amperometric glucose detection was carried out using the same setup, with the potential fixed to $0.5 \mathrm{~V}$. The detection was performed in a $100 \mathrm{mM} \mathrm{NaOH}$ electrolyte with separate glucose administration with increasing concentration 1-fold in the whole volume after three consequent injections of same molarity starting from $10 \mathrm{nM}$ and ending at $10 \mathrm{mM}$ injections. Each injection had a duration of $\sim 10 \mathrm{~s}$ with a $100 \mathrm{~s}$ interval between injections; after injection of $10 \mathrm{mM}$, the interval was increased to $200 \mathrm{~s}$ due to the saturation current rise at a stable and reproducible level. Determination of the specific selectivity to glucose was conducted by adding $1 \mathrm{mM}$ of the following chemicals: D-glucose, sucrose, urea (all supplied by Merck), acetic acid (50\%, supplied by VWR), and uric acid (supplied by Sigma-Aldrich). The sensitivity was derived from the slopes of the fit curves, and the limit of detection (LOD) was calculated using the formula LOD $=3.3 \cdot \frac{\mathrm{sd}}{\mathrm{s}}$, where sd is the standard deviation of the signal in a single step and $s$ is the sensitivity. ${ }^{58}$

\section{RESULTS}

The fabrication of the glucose sensor is illustrated in Figure 1. Flexible Nomex insulation sheets were irradiated with an infrared laser, leading to the formation of a carbon-rich conductive seed layer. The carbon seed layers on the Nomex sheets were used for subsequent electroplating of copper. The copper/carbon composite films were then annealed in a tube furnace under a nitrogen atmosphere. During the cooling step of the heat treatment process, two different approaches were implemented to form either copper microspheroids (Cu-MS) or copper oxide urchins ( $\mathrm{CuO}-\mathrm{U})$. These materials further adhered to a copper electrode that was electroplated onto a laser carbon/Nomex substrate to fabricate the new electrodes. 

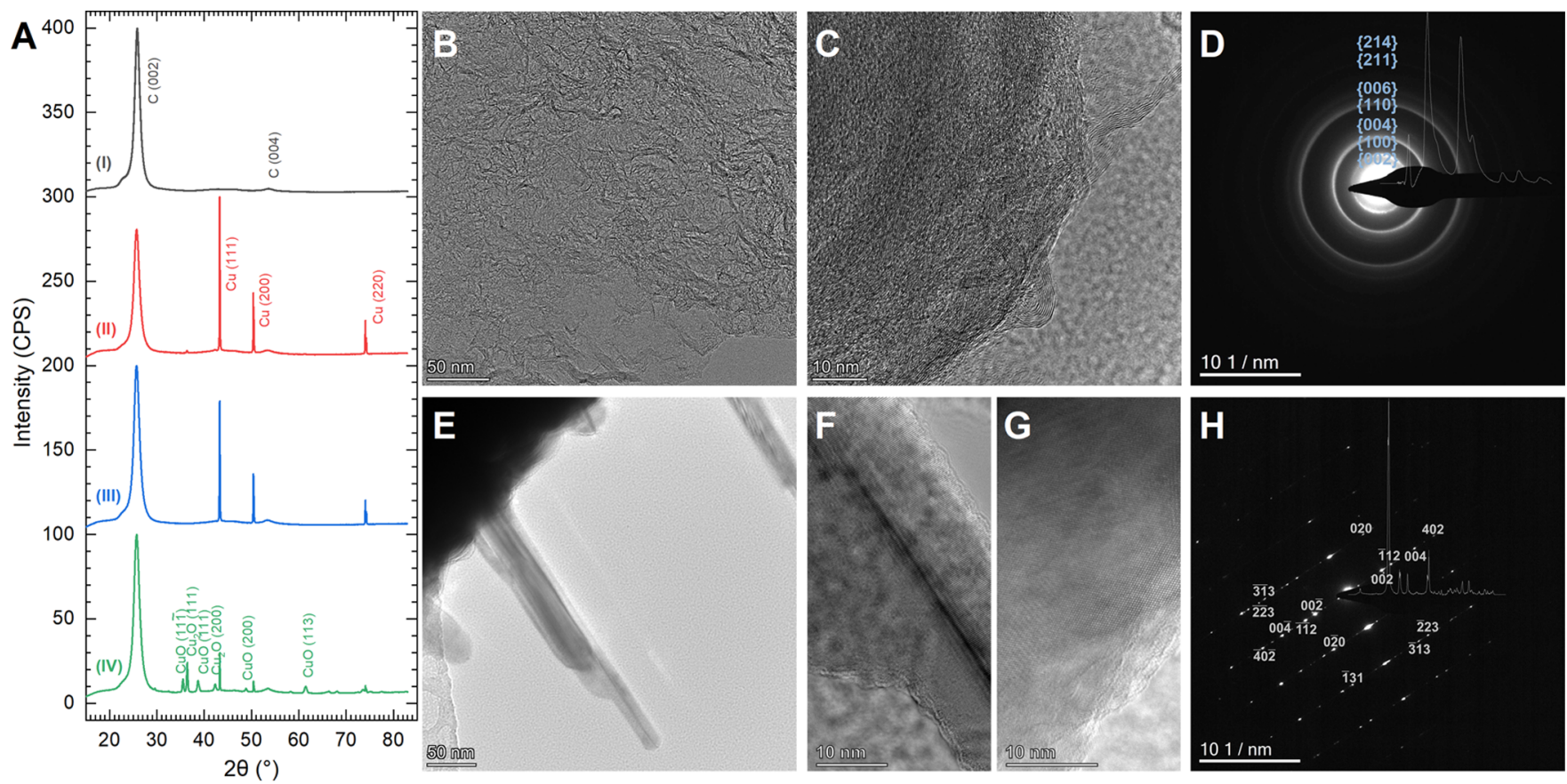

Figure 3. (A) X-ray diffractograms of (I) laser carbon, (II) after copper plating, and the composites (III) Cu-MS and (IV) CuO-U on laser carbon. TEM images from (B, C) laser carbon with (D) SAED. (E) Micrographs of CuO-U with magnified (F) nanowire (monoclinic CuO) and (G) deeper urchin shell (cubic $\mathrm{Cu}_{2} \mathrm{O}$ ) and $(\mathrm{H})$ SAED collected from nanowire.

Figure 2A shows a scanning electron microscopy (SEM) image of the laser carbon film, which featured a porous morphology with a pore size ranging from $\sim 50 \mathrm{~nm}$ to $\sim 10 \mu \mathrm{m}$. The electroplated copper film exhibited a morphology featuring elongated crystals $\sim 3.5 \mu \mathrm{m}$ in length and $\sim 1 \mu \mathrm{m}$ in width, centered at the adhesion site and uniformly distributed across the precursor surface (Figure 2B). The annealing and cooling in the nitrogen environment resulted in aggregation into bigger copper clusters, partially melted and aggregated into microspheroids and nanoparticles (Figure 2C). The shape of such agglomerates, the microspheroids' diameters, their quantity, and uniformity of distribution on laser carbon were directly proportional to the plating duration (Figure S1 and Table S1). However, a plating time higher than $10 \mathrm{~min}$ resulted in the formation of asymmetrical agglomerates, yielding random shapes as shown in Figure S1D. At an annealing temperature below $1000{ }^{\circ} \mathrm{C}$, the plated film did not form any microspheroids, rather, it partially melted and agglomerated into bigger crystals, decreasing the roughness and areal coverage on the underlying laser carbon (Figure S2). Introduction of air at $450{ }^{\circ} \mathrm{C}$ during the cooling step yielded shell oxidation and growth of copper oxide nanowires on $\mathrm{Cu}$ MS, resulting in urchin-like microstructure (Figures 2D and S3) with a small increase in the diameter of the microspheroids (Tables S2 and S3). The morphology was uniform throughout the surface. The CuO-U obtained from a precursor sample with a plating time above $10 \mathrm{~min}$ resulted in a fracturing of the oxidized shell of the microspheroids (Figure S3D). This was caused by excessive stress release, resulting in deterioration of their adhesion to the laser carbon substrate and negatively affecting the sensing capability of the composite electrode. The densely grown nanowires featured diameters ranging from 15 to $150 \mathrm{~nm}$, with lengths up to $5 \mu \mathrm{m}$ as shown in Figure 2E,F. For both types of films, the samples obtained for annealing at $1000{ }^{\circ} \mathrm{C}$ exhibited the highest amperometric response without any significant deterioration of the signal due to saturation (Figure S4). Therefore, these samples were selected for further detailed studies.

Figure 3A depicts X-ray diffractograms of the studied films. Laser carbon features peaks at 25.8, 42.9 , and $53.4^{\circ}$, which are characteristic of a (002) reflection, originating from the perpendicular arrangement of the basal planes in graphite, (100) reflection corresponding to the hexagonal planes, and (004) of second order for the basal plane reflections, respectively. ${ }^{59,60}$ The interplane distances determined using Bragg's law for the (002) and (100) peaks are 3.45 and $2.10 \AA$, respectively, and listed in Table 1 . The XRD pattern of the

Table 1. Crystallographic Properties of the Selected Films after Rietveld Refinement

\begin{tabular}{llccc} 
laser carbon & $\mathrm{C}(002)$ & $\begin{array}{c}\text { interplane } \\
\text { distance }(\AA)\end{array}$ & $\begin{array}{c}\text { crystallite } \\
\text { size }(\mathrm{nm})\end{array}$ & $\begin{array}{c}\text { internal } \\
\text { strain }\end{array}$ \\
electroplated & $\mathrm{C}(002)$ & 3.45 & 56 & 0.002 \\
$\mathrm{Cu}$ & $\mathrm{Cu}(111)$ & 3.47 & 9 & 0.008 \\
$\mathrm{Cu}-\mathrm{MS}$ & $\mathrm{C}(002)$ & 3.09 & 178 & 0.001 \\
& $\mathrm{Cu}(111)$ & 2.09 & 12 & 0.008 \\
$\mathrm{CuO}-\mathrm{U}$ & $\mathrm{C}(002)$ & 3.46 & 265 & 0.013 \\
& $\mathrm{Cu}(111)$ & 2.09 & 265 & 0.008 \\
& $\mathrm{Cu}(1)(111)$ & 2.53 & 75 & 0.013 \\
& $\mathrm{CuO}(11 \overline{1})$ & 2.47 & 75 & 0.343 \\
& & & & \\
\hline
\end{tabular}

electroplated copper featured characteristic peaks of $\mathrm{Cu}$ at $43.3,50.4$, and $74.1^{\circ}$, which correspond to (111), (200), and (220) reflections, and attributed to JCPDS \#04-0836. Cu-MS also exhibited similar peaks. However, the intensity of all peaks dropped slightly, indicating a reduction in the total acquired signal. $\mathrm{CuO}-\mathrm{U}$ films showed a significant reduction in $\mathrm{Cu}$ reflections. In addition, peaks corresponding to $\mathrm{Cu}_{2} \mathrm{O}$ and $\mathrm{CuO}$ appeared in the diffractogram, which matched to JCPDS 


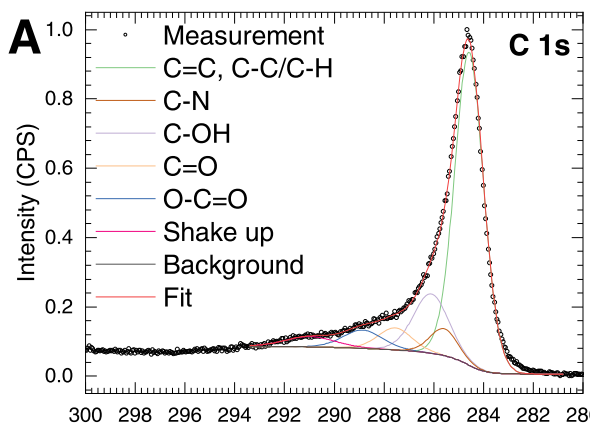

Binding Energy $(\mathrm{eV})$

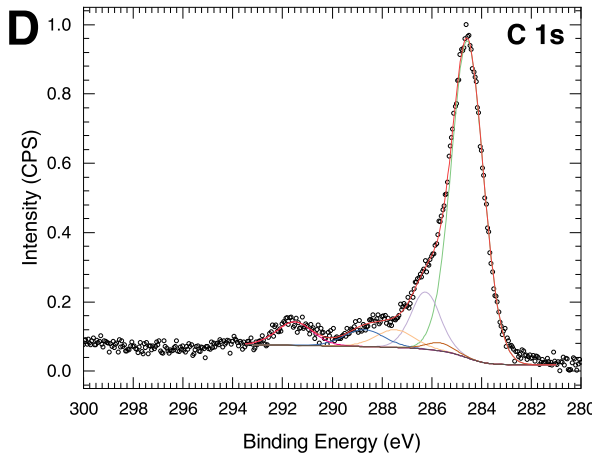

Binding Energy (eV)
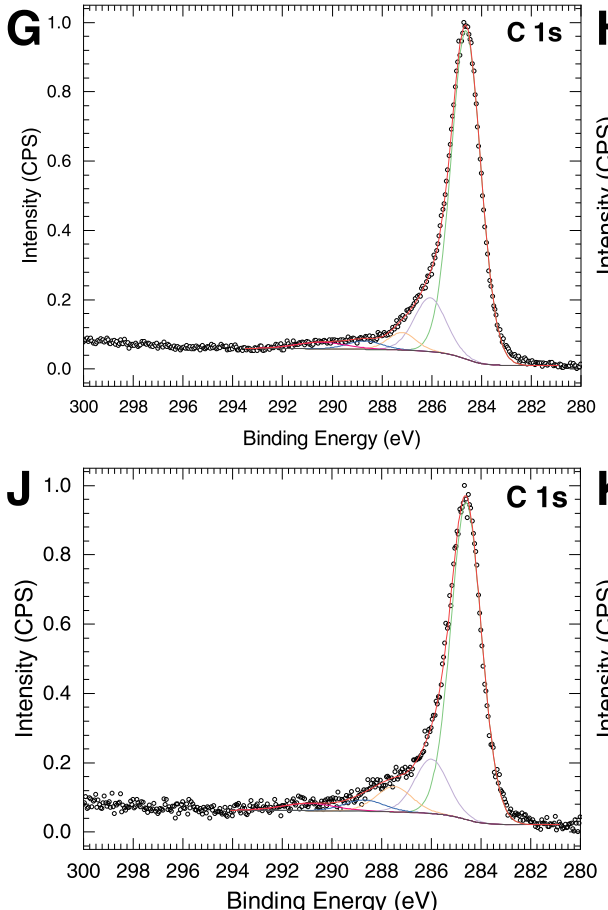

Binding Energy (eV)
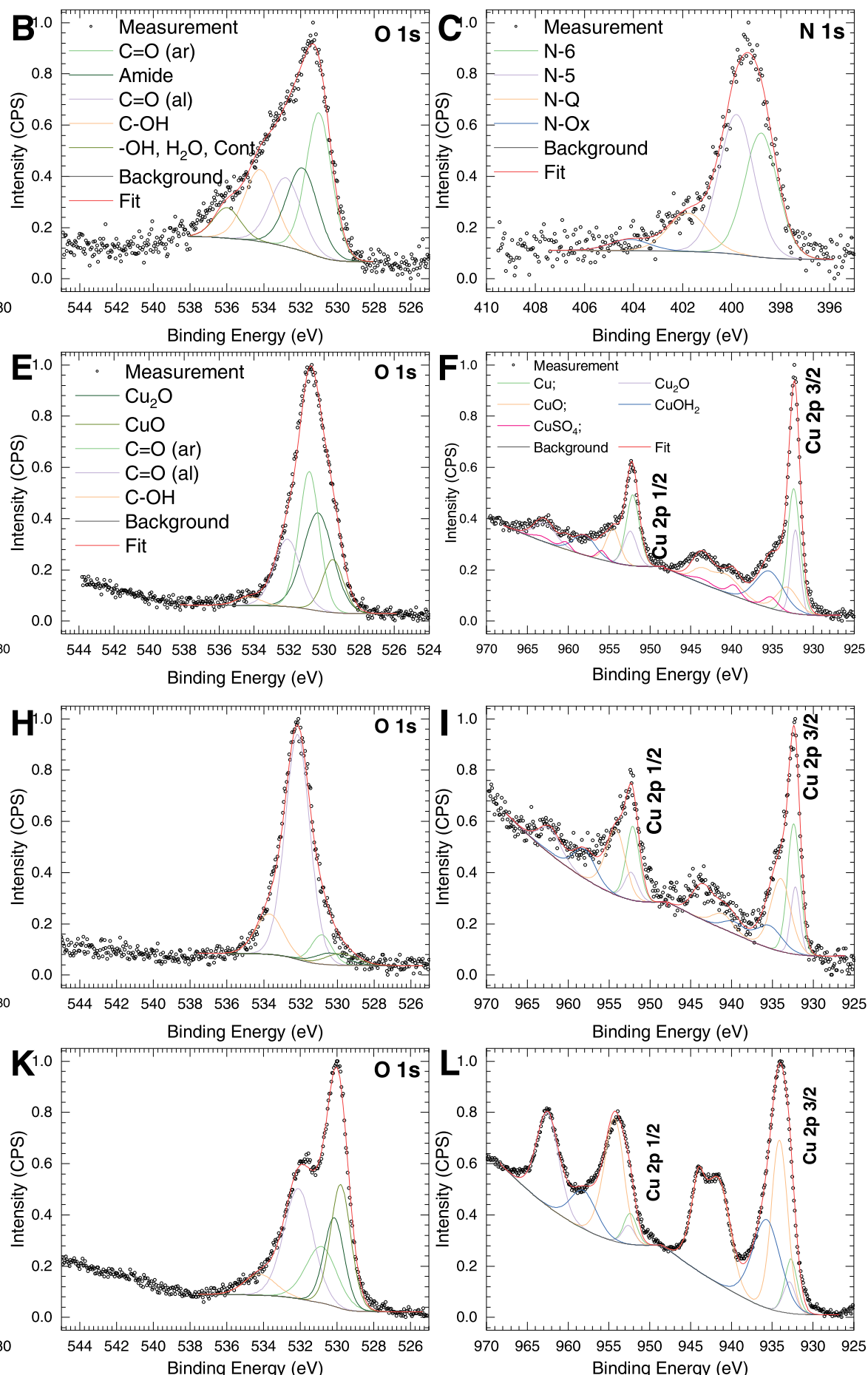

Figure 4. Detailed XPS spectra of $\mathrm{C} 1 \mathrm{~s}, \mathrm{O} 1 \mathrm{~s}, \mathrm{~N} 1 \mathrm{~s}$, and $\mathrm{Cu} 2 \mathrm{p}$ for $(\mathrm{A}-\mathrm{C})$ laser carbon, $(\mathrm{D}-\mathrm{F})$ after electroplating of $\mathrm{Cu}$, and the composites $(\mathrm{G}-$ I) $\mathrm{Cu}-\mathrm{MS}$ and $(\mathrm{J}-\mathrm{L}) \mathrm{CuO}-\mathrm{U}$ on LC.

\#05-0667 (space group $P n \overline{3} m$ ) and \#48-1548 (space group $\mathrm{C} 2 / \mathrm{c}){ }^{61}$ The presence of both chemical modifications confirmed a phase transition of copper to an oxidized phase. The interplane distances were calculated using Bragg's law, and the crystallite sizes and the internal stresses for each component were derived after using Rietveld refinement, ${ }^{56}$ and the results are listed in Table 1. Figures 3B,C and S5 show transmission electron microscopy (TEM) micrographs of laser carbon, featuring thick stacks of graphene sheets and the absence of a long-range order characteristic of polymer-derived carbons. ${ }^{48}$ Additionally, the selected area electron diffraction
(SAED) patterns were collected from the same sample and are depicted in Figure 3D, which exhibits diffusion rings with highorder diffraction patterns previously not detected with XRD. Figures $3 \mathrm{E}-\mathrm{G}$ and $\mathrm{S} 6$ show TEM images from $\mathrm{CuO}-\mathrm{U}$ nanowires and neighboring areas, featuring a long-range order and presence of two phases: cubic $\mathrm{Cu}_{2} \mathrm{O}$ at the Urchin with a unit cell determined at $4.60 \pm 0.34 \AA$, and monoclinic $\mathrm{CuO}$ with a lattice distance of $2.53 \AA$ calculated for the $(11 \overline{1})$ plane. Figure $3 \mathrm{H}$ shows SAED collected from a single nanowire with the electron beam focused along the $[\overline{1} 10]$ orientation with the reflected planes marked accordingly. Raman spectroscopy 

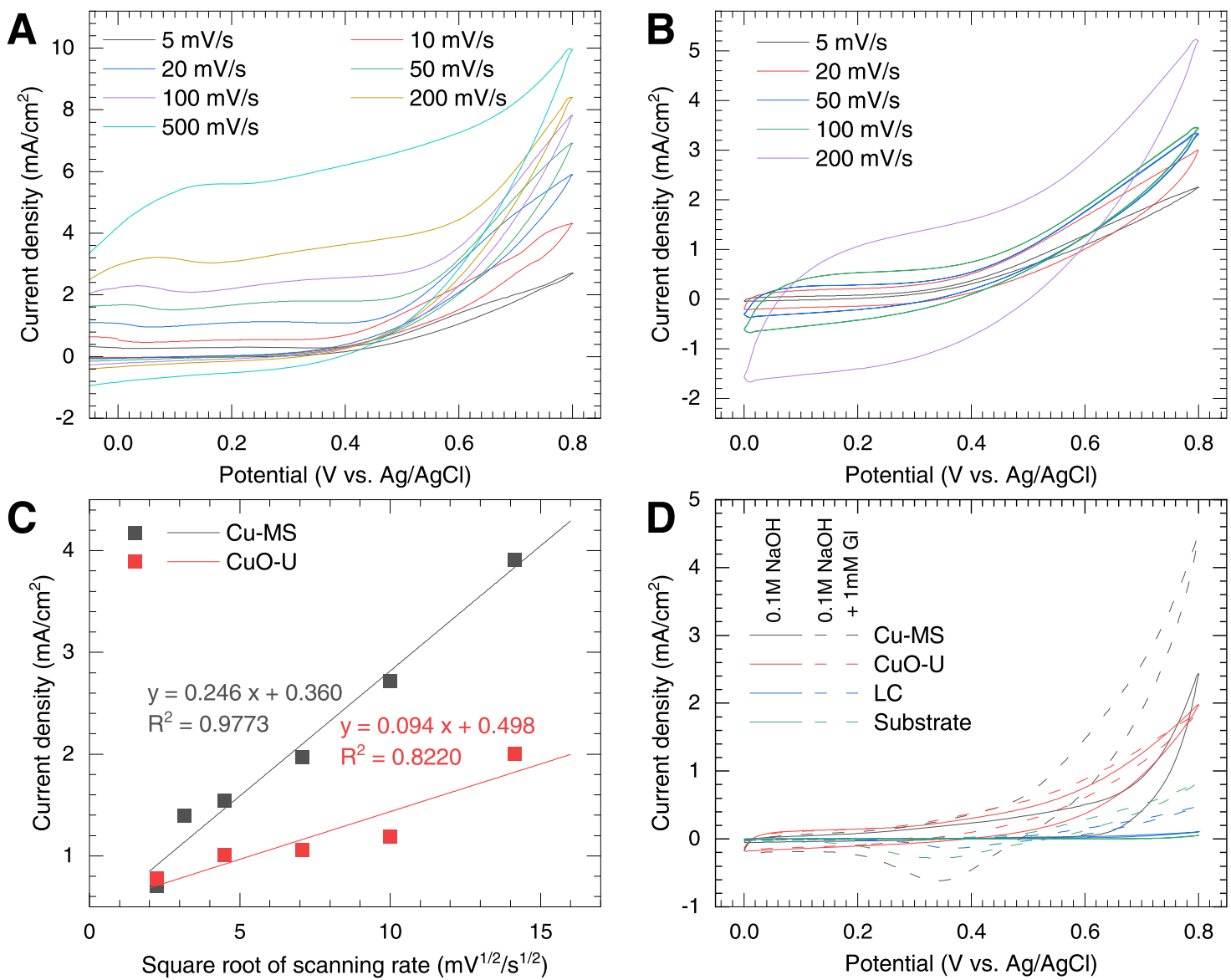

Figure 5. Cyclic voltammograms performed in $100 \mathrm{mM} \mathrm{NaOH}$ and $1 \mathrm{mM}$ glucose with variation of the scanning rate on (A) Cu-MS and (B) CuOU. (C) Oxidation current density at $0.5 \mathrm{~V}$ on the speed of scanning rate. (D) Comparison of the cyclic voltammograms between different substrates performed at a $20 \mathrm{~m} \mathrm{~V} \mathrm{~s}^{-1}$ scan rate in $100 \mathrm{mM} \mathrm{NaOH}$ electrolyte, with and without $1 \mathrm{mM}$ glucose.

further confirmed the formation of laser carbon and $\mathrm{CuO}$ (Figure S7). The Raman spectrum of laser carbon featured the characteristic first-order peaks for the D-band at $1346 \mathrm{~cm}^{-1}$, arising from an $\mathrm{A}_{1 \mathrm{~g}}$ breathing mode of the hexagonal rings at the K-point initiated by disorder, and for the G-band at 1593 $\mathrm{cm}^{-1}$ from an $\mathrm{E}_{2 \mathrm{~g}}$ mode at the $\Gamma$-point, responsible for the stretching vibrations in carbon. ${ }^{62,63}$ In addition, the secondorder $2 \mathrm{D}$ overtone at $2683 \mathrm{~cm}^{-1}$ from sp $\mathrm{sp}^{2}$ carbons and a D + G combinational peak at $2931 \mathrm{~cm}^{-162}$ can also be observed. The calculated intensity ratios $I_{\mathrm{G}} / I_{\mathrm{D}}$ and $I_{2 \mathrm{D}} / I_{\mathrm{G}}$ were 0.68 and 0.21 , respectively. Figure S7B shows the Raman spectrum of the $\mathrm{CuO}-\mathrm{U}$ film, which featured three characteristic peaks of $\mathrm{CuO}$ (inset of Figure S7B) along with the peaks of the laser carbon. The bands in LC shifted insignificantly from the reference values, and the $I_{\mathrm{G}} / I_{\mathrm{D}}$ and $I_{2 \mathrm{D}} / I_{\mathrm{G}}$ ratios were 0.69 and 0.25 , respectively, suggesting improvement in the graphitization of the carbon materials. The $\mathrm{CuO}$ peaks originate from 3 Raman active modes, out of 11 possible optical modes, which correspond to $A_{g}$ at $294 \mathrm{~cm}^{-1}$ and two $B_{g}$ modes at 341 and $627 \mathrm{~cm}^{-1} \cdot 32,64,65$ The positions of these bands matched with Raman shift toward the lower wavenumbers for nanocrystalline powders, ${ }^{64}$ which further confirmed the crystallite sizes determined with the XRD.

Surface chemical compositions of the fabricated films were studied using X-ray photoelectron spectroscopy (XPS). The survey spectrum is shown in Figure S8, which features the presence of $\mathrm{C} 1 \mathrm{~s}, \mathrm{O} 1 \mathrm{~s}$, and $\mathrm{N}$ 1s peaks in laser carbon, and a peak of $\mathrm{Cu} 2 \mathrm{p}$ was observed after plating and annealing. A few contaminants were also detected on the surface. For example, peaks of $\mathrm{Na}$ 1s and Auger $\mathrm{Na}_{\mathrm{KLL}}$ were observed in the XPS spectra of the laser carbon sample, which might have originated from the manufacturing process of the Nomex sheets. The spectra for copper-coated films featured visible peaks of $F 1$ s, S 2 p, and Si $2 p$, which might have originated from the electroplating bath and precipitation of silicon nanoparticles during dicing of the glass slide. After the annealing procedures, the presence of these contaminants was significantly reduced. However, the spectra of the annealed samples featured insignificant contributions from $\mathrm{Al} 2 \mathrm{p}$, which probably originated from sample handling. Table S4 indicates total atomic composition corrected to the elements of interest for each studied film. Figure 4 presents deconvoluted $\mathrm{C} 1 \mathrm{~s}$ and O 1s XPS spectra of all of the four types of samples. Deconvoluted $\mathrm{N}$ 1s spectrum was collected only for laser carbon, due to its significant contribution, whereas $\mathrm{Cu} 2 \mathrm{p}$ spectra were collected from the samples obtained after plating and annealing.

The $\mathrm{C}$ 1s peaks of the XPS spectra of each sample (Figure $4 \mathrm{~A}, \mathrm{D}, \mathrm{G}, \mathrm{J})$ are deconvoluted into six species: $\mathrm{C}=\mathrm{C}, \mathrm{C}-\mathrm{C} / \mathrm{C}-$ $\mathrm{H}$ at $284.6 \mathrm{eV}, \mathrm{C}-\mathrm{N}$ at $285.6 \mathrm{eV}$, a hydroxyl $(\mathrm{C}-\mathrm{OH})$ at 286.1 $\mathrm{eV}$, a carbonyl $(\mathrm{C}=\mathrm{O})$ at $287.4 \mathrm{eV}$, a carboxyl $(\mathrm{HO}-\mathrm{C}=\mathrm{O})$ at $288.8 \mathrm{eV}$, and $\pi-\pi^{*}$ shake-up at $291.0 \mathrm{eV}^{40,48,66,67}$

The fitting was reduced to five species of both samples obtained after annealing (Figure 4G,J), and the $\mathrm{C}-\mathrm{N}$ species was removed due to insignificant contribution from the $\mathrm{N} 1 \mathrm{~s}$ peak. Figure 4B,E,H,K shows the O 1s peak, which featured 

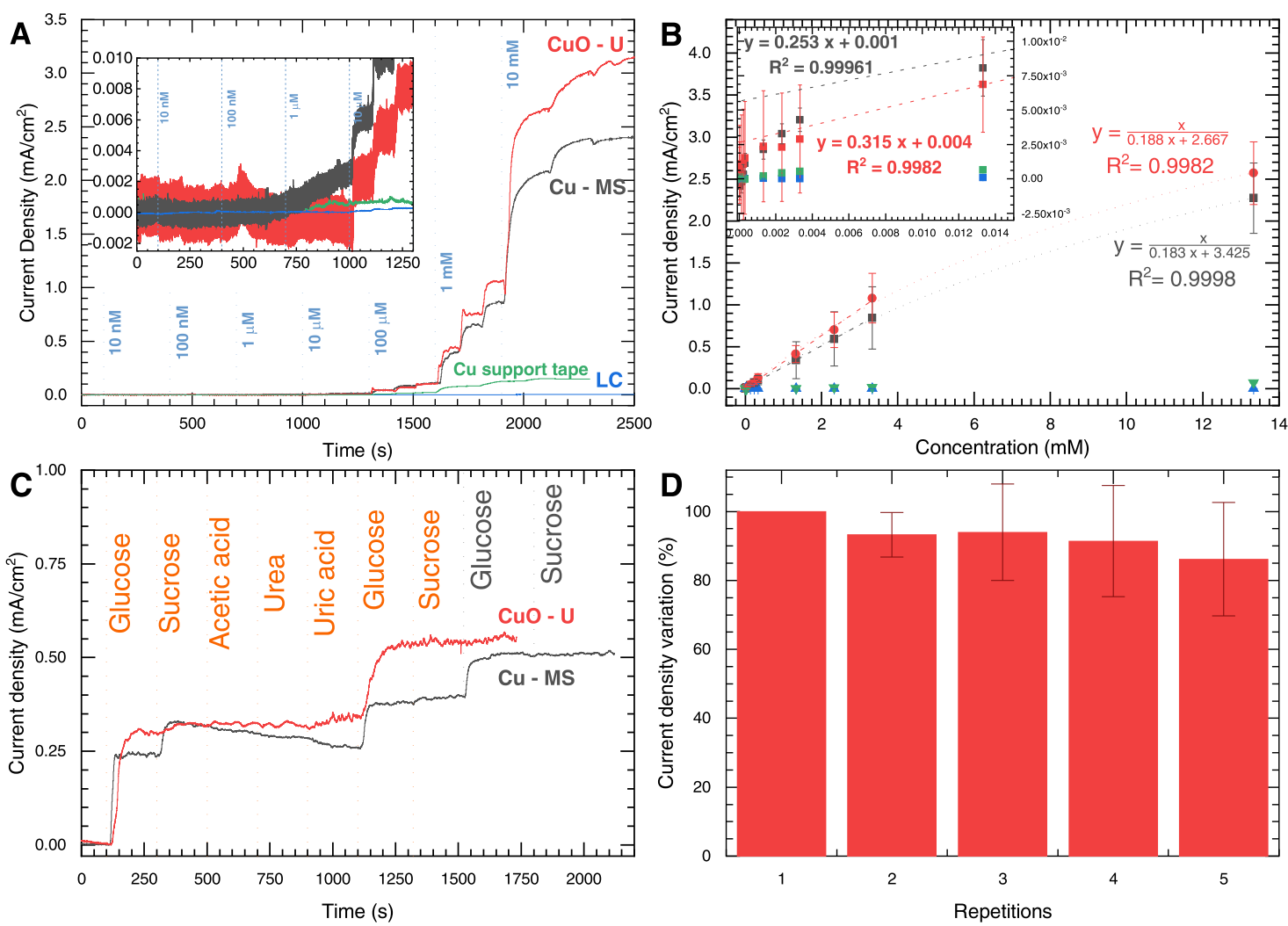

Figure 6. (A) Temporal amperometric response by a stepwise increase of the glucose concentration in a $100 \mathrm{mM} \mathrm{NaOH}$ electrolyte. (B) The extracted calibration curves of a current response versus the glucose concentration (same color map as for (A)). (C) Amperometric response of the composite films by a consecutive addition of $1 \mathrm{mM}$ of each of the indicated analytes. (D) Amperometric signal reduction after multiple uses.

three species in all samples, including an aromatic carbonyl at $530.9 \mathrm{eV}$, an aliphatic carbonyl at $532.3 \mathrm{eV}$, and a hydroxyl at $534.1 \mathrm{eV} .^{40,48,68}$ The fitting for laser carbon was performed with an additional species from amide at $531.9 \mathrm{eV}^{69}$ and overlapping with some minor contamination originated from a hydroxyl group, chemisorbed water, and possible Auger $\mathrm{Na}_{\mathrm{KLL}}$, which were fitted in one peak at $536.0 \mathrm{eV} .^{70,71}$ The $\mathrm{O} 1 \mathrm{~s}$ peak (Figure 4E,H,K) after deposition of copper featured two supplementary species, which were a cupric oxide $(\mathrm{CuO})$ at $529.7 \mathrm{eV}$ and a cuprous oxide $\left(\mathrm{Cu}_{2} \mathrm{O}\right)$ at $530.3 \mathrm{eV}$. Figure $4 \mathrm{C}$ shows the deconvolution of the $\mathrm{N} 1 \mathrm{~s}$ peak into four nitrogencontaining species: a pyridinic $(\mathrm{N}-6)$ at $398.80 \mathrm{eV}$, a pyrrolic $(\mathrm{N}-5)$ at $399.8 \mathrm{eV}$, a quaternary/graphitic $(\mathrm{N}-\mathrm{Q})$ at $401.8 \mathrm{eV}$, and an oxidic $(\mathrm{N}-\mathrm{Ox})$ at $404.2 \mathrm{eV}^{48,66,72,73}$ Figure 4F,I,L shows $\mathrm{Cu} 2 \mathrm{p}$ peaks, which were fit into the five species: a copper, a cuprous oxide, a cupric oxide, a copper hydroxide $(\mathrm{CuOOH})$, and a copper sulfate $\left(\mathrm{CuSO}_{4}\right) \cdot{ }^{32,74,75}$ The contribution from copper sulfate after annealing was negligible and was therefore omitted in the further analysis. The detailed results after the deconvolution of all spectra are presented in Table S5.

The electrochemical properties of the annealed films $(\mathrm{Cu}-$ $\mathrm{MS}$ and $\mathrm{CuO}-\mathrm{U}$ ) were investigated using cyclic voltammetry $(\mathrm{CV})$. The redox potentials were observed within the potential range -0.8 to $0.8 \mathrm{~V}$ for both samples, as shown in Figure S9. The electrochemical measurements were independently performed in the initial alkaline electrolyte, in the presence and absence of $1 \mathrm{mM}$ glucose and independently with sucrose. Figure S9A shows cyclic voltammograms of the Cu-MS films. The oxidation peaks were observed at -0.32 and $-0.10 \mathrm{~V}$, which can be attributed to the transition from $\mathrm{Cu}^{0}$ to $\mathrm{Cu}^{1+}$
$\left(\mathrm{Cu}_{2} \mathrm{O}\right)$ and from $\mathrm{Cu}^{0}$ and $\mathrm{Cu}^{1+}$ to $\mathrm{Cu}^{2+}(\mathrm{CuO})$, respectively. The reduction was observed at -0.54 and $-0.74 \mathrm{~V}$, which correspond to the transition from $\mathrm{Cu}^{2+}$ to $\mathrm{Cu}^{1+}$ and then to $\mathrm{Cu}^{0}{ }^{76-78}$ The addition of glucose to the electrolyte resulted in a decrease in the intensities of all of the peaks, and a shift of the oxidation peak to $-0.23 \mathrm{~V}$, which was due to the transition from $\mathrm{Cu}^{0}$ to $\mathrm{Cu}^{1+} \cdot{ }^{76,77}$ Figure S9B shows $\mathrm{CV}$ curves of the $\mathrm{CuO}-\mathrm{U}$ film. Notably, the oxidation peaks were observed at -0.02 and $0.05 \mathrm{~V}$, which were attributed to the transition from $\mathrm{Cu}^{1+}$ to $\mathrm{Cu}^{2+}$ and from $\mathrm{Cu}^{2+}$ to $\mathrm{Cu}^{3+}$, respectively. The reduction current featured a peak at $-0.60 \mathrm{~V}$, which were due to the transition from $\mathrm{Cu}^{3+}$ to $\mathrm{Cu}^{2+}$ and from $\mathrm{Cu}^{3+}$ to $\mathrm{Cu}^{1+}$, respectively. The presence of glucose significantly improved the oxidation and reduction of $\mathrm{Cu}^{2+}$. The chemical formulas for the involved reactions are presented in Figure S10A.

As the glucose molecules mainly yielded an oxidative behavior on the electrode materials, we studied the oxidation current in detail to characterize the sensing behavior. The cyclic voltammograms of $\mathrm{Cu}-\mathrm{MS}$ and $\mathrm{CuO}-\mathrm{U}$ electrodes are presented in Figure 5A,B, respectively. The oxidation peak current increased with an increase in the scanning rate for both the electrodes, due to the fast oxygen transfer to the working electrode promoting an uncompensated solution ohmic drop. ${ }^{79}$ Figure 5C shows an increase of the oxidation current proportional to the square root of the scanning rate and shows a linear dependence, indicating only diffusive behavior in the electrocatalytic glucose oxidation, which is advantageous for amperometric sensing. ${ }^{77}$ However, Cu-MS film exhibited a steeper slope, supporting the improved oxidation rate from $\mathrm{Cu}^{0}$ compared to the $\mathrm{CuO}$ counterpart. As depicted in Figure $5 \mathrm{D}$, the electrochemical studies showed that $\mathrm{Cu}-\mathrm{MS}$ and $\mathrm{CuO}$ - 
Table 2. Comparison of Flexible and Carbon-Based Glucose Sensors

\begin{tabular}{|c|c|c|c|c|c|}
\hline electrode & detection potential $(\mathrm{V})$ & sensitivity $\left(\mathrm{mA} \mathrm{cm}-2 \mathrm{mM}^{-1}\right)$ & linear range $(\mathrm{mM})$ & LOD $(\mu \mathrm{M})$ & ref \\
\hline $\mathrm{Cu}-\mathrm{MS} / \mathrm{LC}$ & 0.50 & 0.25 & $0.001-3.3$ & 1.75 & this work \\
\hline $\mathrm{CuO}-\mathrm{U} / \mathrm{LC}$ & 0.50 & 0.32 & $0.001-3.3$ & 7.56 & this work \\
\hline $\mathrm{CuO} /$ graphene & 0.55 & 1.36 & $0.002-4$ & 0.70 & 24 \\
\hline $\mathrm{Cu}$ nanowire/graphene & 0.60 & 1.10 & $0.005-6$ & 1.60 & 25 \\
\hline $\mathrm{CuO} / \mathrm{MWCNT}$ & 0.55 & 2.19 & $0.001-3$ & 0.80 & 26 \\
\hline $\mathrm{CuO}$ NW/SWCNT & 0.60 & 2.19 & $0.001-0.034$ & 0.05 & 27 \\
\hline Naflon/CuO/GC & 0.60 & 0.41 & $0.05-2.55$ & 1.00 & 28 \\
\hline $\mathrm{Cu} / \mathrm{MnO}_{2} / \mathrm{GC}$ & 0.70 & 0.38 & $0.25-1.02$ & 0.10 & 29 \\
\hline $\mathrm{Pt}-\mathrm{NiO} / \mathrm{rGO} / \mathrm{GC}$ & 0.50 & 0.83 & $0.008-14.5$ & 2.67 & 30 \\
\hline $\mathrm{Ni}-\mathrm{SnO}_{x} / \mathrm{PANI} / \mathrm{CuO}$ & 0.65 & $1.63 ; 1.33$ & $0.001-1 ; 1-10$ & 0.13 & 37 \\
\hline
\end{tabular}

U films exhibited significantly superior performance while compared to laser carbon and the supporting copper tape. With the presence of $1 \mathrm{mM}$ glucose in the electrolyte, the total area of the CV curve and the peak current increased for all of the studied films.

Figure 6A shows the real-time amperometric response of the $\mathrm{Cu}-\mathrm{MS}$ and $\mathrm{CuO}-\mathrm{U}$ electrodes, after consequent injection of glucose of different molarity starting from $10 \mathrm{nM}$ to $10 \mathrm{mM}$ in the $100 \mathrm{mM} \mathrm{NaOH}$ electrolyte at $0.5 \mathrm{~V}$. The potential at $0.5 \mathrm{~V}$ was selected because a significant improvement of the current response in the $\mathrm{CV}$ was observed for the $\mathrm{CuO}$ film in the presence of glucose (Figure 5D). For comparison, the amperometric response of the laser carbon film and the supporting copper tape is also presented, each of which exhibited only a minor contribution to the total signal during the amperometric measurement. The calibration curves for both test samples are plotted in Figure $6 \mathrm{~B}$ and follow a linear dependency on the glucose concentration up to $3 \mathrm{mM}$. Notably, the CuO-U electrode exhibited a more uniform steplike signal at a low concentration and featured a saturation of the current density at a glucose concentration of over $10 \mathrm{mM}$. The linear range of the amperometric response for both films was fit from $1 \mu \mathrm{M}$ to $3 \mathrm{mM}$, with an $R^{2}$ of 0.9996 and 0.9982 for the $\mathrm{CuO}-\mathrm{U}$ and $\mathrm{Cu}-\mathrm{MS}$, respectively. The nonlinear (hyperbolic) function as well can be used for fitting improvement for concentrations starting from minimal at 1 $\mu \mathrm{M}$ and allows extension of the sensitivity range to $10 \mathrm{mM}$. The sensitivity of the $\mathrm{CuO}-\mathrm{U}$ and $\mathrm{Cu}-\mathrm{MS}$ electrodes was 0.25 and $0.32 \mathrm{~mA} \mathrm{~cm}^{-2} \mathrm{mM}^{-1}$, respectively, whereas the lower limits of detection (LODs) of these electrodes were 1.74 and $7.56 \mu \mathrm{M}$, respectively. Some increase in amperometric signal was observed after injecting $100 \mathrm{nM}$ glucose, but because the high signal-to-noise ratio cannot reliably derive, all fits were initiated from $1 \mathrm{mM}$. The comparison to other reported values for carbon-based sensors is presented in Table 2. Figure 6C shows the selective current response of our electrode materials upon addition of $1 \mathrm{mM}$ glucose, sucrose, acetic acid, urea, and uric acid, finalized with a control glucose addition. Cu-MS were additionally verified by a complementary addition of sucrose and glucose due to the observed response in the presence of the sucrose. In comparison, the $\mathrm{CuO}-\mathrm{U}$ electrode exhibited specific selectivity only to glucose.

To understand such specificity, we studied the redox reactions on the electrodes in the presence of sucrose. In the presence of sucrose, an additional oxidation peak appeared in the CV curve for the Cu-MS electrode (Figure S9) at $0.60 \mathrm{~V}$, which can be attributed to the oxidation of $\mathrm{Cu}^{2+}$ to $\mathrm{Cu}^{3+}$ $(\mathrm{CuOOH}) .{ }^{11}$ Such an oxidation reaction leads to the hydrolysis of sucrose to fructose and glucose in an alkaline solution. The glucose converts to a gluconolactone, and further, a gluconic acid, ${ }^{80}$ as shown in Figure S10B. Figure S11 shows the detailed electrochemical analysis of the Cu-MS electrode in the presence of the sucrose. The amperometry on the $\mathrm{Cu}-\mathrm{MS}$ was performed by consecutive addition of sucrose. The results are presented in Figure S11C, which exhibited deterioration of the signal with an increase in concentration. This resulted in a shorter linear range from 1 to $30 \mu \mathrm{M}$ with $R^{2}$ $=0.969$.

The $\mathrm{CuO}-\mathrm{U}$ film exhibited the presence of the majority $\mathrm{Cu}^{2+}$ oxide species and shows its retention after the amperometry tests, without any chemical modification, as was observed earlier via $\mathrm{CV}$ tests in Figures $5 \mathrm{~A}$ and S9B. Due to this factor, the $\mathrm{CuO}-\mathrm{U}$ film was selected for the test involving multiple repetitions, followed by rinsing in DI water after each cycle, and for the complementary bending tests of the composite electrode. Figure $6 \mathrm{D}$ shows retention of the amperometric response after multiple repetitions, whereas the signal shows a deviation of around 15\% after five cycles.

Such a low-cost glucose sensor was additionally tested after flexing at $\pm 90^{\circ}$ and is presented in Figure S12. However, it suffered from significant deterioration of the signal at a low concentration and exhibited signal response from 4 to $\sim 60$ $\mathrm{mM}$, which was fit with linear function, attributing reduction of the sensitivity to $0.072 \mathrm{~mA} \mathrm{~cm}{ }^{-2} \mathrm{mM}^{-1}$. All of these changes can be attributed to the reduction of the sensing area and the poor electrical connection between the electrode and electroplated copper. Further improvement for flexible sensors can be performed by implementing conductive adhesive or providing additional plating on the back side of the electrode, which lays out of the scope of the current paper.

The surface morphology and chemistry after the last amperometric measurement were studied with the SEM depicted in Figure S13 and the EDX in Figure S14, respectively. The population of $\mathrm{Cu}-\mathrm{MS}$ and $\mathrm{CuO}-\mathrm{U}$ microparticles decreased $\sim 7$ and $\sim 15 \%$, respectively. Notably, the nanometric features, nanowires, and particles from both substrates almost completely detached after amperometric testing. Due to such reduction, the chemical composition of copper significantly decreased in both cases, as depicted in Figure S15. The substrate does not feature significant oxidation and most of the oxygen is bonded with the microparticles. Figure S15B features estimation of the copper to oxygen ratio, showing an increase in the oxidation in Cu-MS and a decrease in $\mathrm{CuO}-\mathrm{U}$. The latter corresponds to the nanowire detachment and the exposition of the $\mathrm{Cu}_{2} \mathrm{O}$ core below the $\mathrm{Cu}$ shell of the urchin. 


\section{DISCUSSION}

Laser-induced carbonization is a rapid process for the thermochemical conversion of a polymer to a carbon material, which is induced by photochemical and photothermal mechanisms, ${ }^{39,40,42}$ analogous to conventional thermal pyrolysis in a furnace. The accumulated heat over the polymer surface provides a sufficiently high-temperature gradient for carbonization at a focal spot and a surrounding heat-affecting zone, involving a rapid expulsion of byproducts such as $\mathrm{CNH}$, $\mathrm{CO}, \mathrm{CO}_{2}, \mathrm{H}_{2} \mathrm{O}$, and complex aromatic hydrocarbons. ${ }^{81,82}$ It has been reported that Nomex films exhibit a high carbon yield for LIC and require multiple passes of lasing for improvement of crystallinity and conductivity. ${ }^{43,44}$ Lattice parameters of the Nomex-derived laser carbon indicate a high degree of graphitization with an interlayer distance and crystalline sizes comparable to commercial graphite and superior to that obtained from the traditional furnace-based pyrolysis of Nomex. ${ }^{44}$ The XRD pattern of the Nomex-derived laser carbon (Figure 3A) exhibited a high degree of graphitization with a crystalline size of $56 \mathrm{~nm}$. SAED, collected from laser carbon, confirmed the high graphitization by the appearance of high-order diffraction patterns, with families of $\{211\}$ and $\{214\}$ planes, which were not observed with XRD. TEM imaging supported the presence of thick stacks of long graphene sheets randomly distributed within a crystal comparable to glassy carbon, ${ }^{83}$ which is depicted in Figures $3 \mathrm{C}$ and S5. In support of the XRD pattern and TEM imaging, Raman spectra of the carbon film featured a narrow width of the $D$ and $G$ bands (Figure S7). After annealing of the electroplated films, the bandwidth decreased and $I_{\mathrm{G}} / I_{\mathrm{D}}$ was improved. This can be attributed to the reduction of the heteroatom species and the alignment of the graphene sheets.

The high degree of graphitization of the laser carbon film is further confirmed by XPS, where the C 1 s spectral line is centered at $284.6 \mathrm{eV}$, corresponding to an $\mathrm{sp}^{2}$-hybridized state. $^{48,66,67}$ The tail in the C 1s peak indicates the presence of multiple functional groups with nitrogen and oxygen heteroatoms. In pairs, the deconvoluted $\mathrm{N} 1 \mathrm{~s}$ peak is attributed to multiple configurations. Within the graphene sheets, the nitrogen heteroatoms are incorporated as $\mathrm{N}-\mathrm{Q}$, and at the edge of the graphene sheet, the heteroatoms form pyridinic and pyrrolic rings and an additional $\mathrm{N}-\mathrm{O}_{\mathrm{x}}$ species corresponds to amides. The amide species propagate after LIC by bond dissociation along the $\mathrm{C}-\mathrm{N}$ bond, due to the lowest enthalpy in the chain at this site, which transforms and leaves some residue in the form of amide. ${ }^{66}$ The processing in an ambient environment (air) influences oxidation of dissociated species and promotes the incorporation of nitrogen into the graphene lattice. The oxygen conjugated species were observed in the $\mathrm{O}$ 1s line, which was present in multiple conformations with some preference at the aromatic carboxyl site in the graphene sheet. Other species were reduced but not observed in an equivalent rate to each other. This suggests an initial scission along the $\mathrm{C}-\mathrm{N}$ bonds, with further bonding into a hexagonal graphene-like lattice. ${ }^{84}$ Across all samples, the carbon base from the $\mathrm{C} 1 \mathrm{~s}$ line does not significantly change, indicating relatively close contribution to each functional group.

A laser carbon film serves as a preferable seed layer for the electroplating of copper. ${ }^{44}$ The presence of heteroatoms in the graphene sheets bolsters charge accumulation at their sites, in the case of both oxygen and nitrogen conjugated species. ${ }^{85}$ The site provides a higher negative potential on the Allen electronegativity scale compared to carbon, thus inducing preferred oxidation of $\mathrm{Cu}$ ions during electroplating and passivating the heteroatom charge. This was confirmed by the reduction of heteroatom species observed in XPS C 1s peaks in Figure $4 \mathrm{D}$ and by the shift of the $\mathrm{O} 1 \mathrm{~s}$ spectrum toward $\mathrm{CuO}$ and $\mathrm{Cu}_{2} \mathrm{O}$ species reducing contribution from a hydroxyl functional group (Figure $4 \mathrm{E}$ ). As was observed from $\mathrm{Cu} 2 \mathrm{p}$ in Figure $4 \mathrm{~F}$, the surface featured not only a metallic $\mathrm{Cu}$ but also additional $\mathrm{Cu}_{2} \mathrm{O}, \mathrm{CuO}$, and $\mathrm{Cu}(\mathrm{OH})_{2}$ species, due to the immediate oxidation of the film in air, and some contamination from the $\mathrm{CuSO}_{4}$ electrolyte in a minor concentration, fit with a standard spectrum for each species. ${ }^{75}$

Annealing of the copper/carbon composite film showed persistent low diffusion of the carbon into the copper, due to its low solubility, as is indicated in the specific phase diagrams. ${ }^{86}$ The annealing of thin copper films at $1000{ }^{\circ} \mathrm{C}$ promoted melting and led to aggregation as droplets (microspheroids) on laser carbon, induced by heterogeneous melting with reduced Gibbs free energy for the thin films. ${ }^{87,88}$ The surface energies of copper and carbon are 1.79 and $0.26 \mathrm{~J}$ $\mathrm{cm}^{-2}$ respectively, ${ }^{89}$ which also support the aggregation of the molten copper into microspheroids by a reduction of the contact area, due to the significantly higher surface energy, causing nonwetting of the copper on the laser carbon. ${ }^{90}$ The surface roughness further promoted the contact area reduction by copper. ${ }^{90}$ The reduced surface coverage due to the molten copper further yielded a reduced signal intensity in XRD and XPS. Figure $4 \mathrm{G}$ indicates improvement in the areal contribution and narrowing the width of the $\mathrm{C}=\mathrm{C}, \mathrm{C}-\mathrm{C}$ / $\mathrm{C}-\mathrm{H}$ peak, caused by redistribution and cleavage of heteroatoms in the lattice. ${ }^{91}$ This was confirmed by the observed $\mathrm{O}$ 1s peaks, where the carboxyl groups are present mainly in their aliphatic form (Figure $4 \mathrm{H}$ ).

The introduction of air during cooling at $450{ }^{\circ} \mathrm{C}$ induced a copper nanowire growth, which was promoted by a vaporsolid growth mechanism. ${ }^{92}$ With an excess of oxygen, a $\mathrm{Cu}_{2} \mathrm{O}$ phase formed, fostering hillock aggregation due to relief of compressive stresses. At temperatures above $400{ }^{\circ} \mathrm{C}$, the $\mathrm{Cu}_{2} \mathrm{O}$ phase is not thermodynamically stable. Therefore, with further oxygen supply, the nanowires of $\mathrm{CuO}$ started growing, with the hillocks as the nucleation sites. ${ }^{55,92,93}$ These results were confirmed through analysis of the XRD patterns, indicating the presence of both phases. This mechanism of nanowire growth was further confirmed with TEM (Figure $3 E-G$ ). Within the top $5 \mathrm{~nm}$ of the urchin shell, crystallites with layered or random orientation were found, characteristic for a monoclinic $\mathrm{CuO}$ lattice or an intermediate amorphous phase. As is seen in Figures $3 \mathrm{G}$ and S6, above $5 \mathrm{~nm}$ within the shell, the structure featured an initial cubic lattice specific to $\mathrm{Cu}_{2} \mathrm{O}$ with a matching unit cell size. ${ }^{55,92}$ At the nucleation site and in the grown nanowire, the crystal structure attained a stacked layer structure, and further along the length of the crystal featured the moire fringes due to an overlapping of the different crystal orientations. The core nanowire crystallite was circularly surrounded by a shell. The SAED pattern confirmed the sole presence of the $\mathrm{CuO}$ phase and exhibited a splitting, due to the presence of two crystallographic orientations. Rietveld's refinement of the XRD further showed an increase in the internal stress in both oxidized states compared to the remaining $\mathrm{Cu}$. Notably, $\mathrm{Cu}_{2} \mathrm{O}$ shells exhibited lower internal stress, due to stress-induced growth of $\mathrm{CuO}$ nanowires, ${ }^{55,92}$ which can be further reduced by an increase in the annealing time. 
The detailed XPS spectra in Figure 4K,L, and summary Table S5, confirmed the oxidation of the film with a shift to the dominant $\mathrm{CuO}$ and $\mathrm{Cu}(\mathrm{OH})_{2}$ functional groups, with a minor contribution from $\mathrm{Cu}_{2} \mathrm{O}$, due to the short duration of the annealing step. The contribution from chemical species could be tailored with temperature and the duration of annealing. ${ }^{54}$

Both types of composite films were further utilized for enzyme-free glucose detection. Unlike $\mathrm{Cu}-\mathrm{MS}, \mathrm{CuO}$ retained its chemical composition after a number of cycles, which was observed by the redox reactions during CV (Figure S9). After the injection of glucose, the oxidation current significantly increased, as is seen in Figure 5D. Such an increase occurred in micro- and nanostructured copper, which provided sufficient surface area for the oxidation of the metal via the formation of gluconolactone and, furthermore, gluconic acid in the presence of the analyte in the alkaline electrolyte ${ }^{80}$ (see the equations in Figure S10A).

Despite the presumed higher surface-to-volume ratio of the $\mathrm{CuO}-\mathrm{U}$ compared to $\mathrm{Cu}-\mathrm{MS}$, both materials attained insignificant differences in the amperometric response (Figure $6 \mathrm{~A}, \mathrm{~B})$. The equivalent responses of both electrodes were supported by the dispersion of $\mathrm{Cu}$ nanoparticles in addition to the microspheroids on laser carbon film after annealing, which provide an improvement of the total sensing area. The presence of transition-metal nanoparticles induces the glucosesensing ability of the electrode due to an increase in the sensing surface area. ${ }^{20,47}$ However, both films exhibited saturation in the amperometric signal for a glucose concentration over $\sim 10 \mathrm{mM}$. As we hypothesized, this might have occurred due to constraining of the metal oxidation and a fast saturation at the active sites with hydroxyl species. On the other hand, the $\mathrm{Cu}-\mathrm{MS}$ electrode featured a difference in the oxidation kinetics for the microspheroids and the nanoparticles and in line with previously reported values for the metal nanoparticles. ${ }^{8,20}$ Nevertheless, the $\mathrm{CuO}-\mathrm{U}$ electrode exhibited the highest sensitivity due to the superior electron transfer for the material at the selected overpotential, ${ }^{11}$ supported by a nanostructured morphology, as is observed from CV (Figure $5 \mathrm{D})$. Both electrodes tested here exhibited similar performance in terms of linear range, sensitivity, but suffered from a higher LOD of glucose, compared to carbon-based glucose sensors reported by other authors, as shown in Table 2 . Limited and uneven distribution of the nanostructured active sites responsible for the glucose oxidation results in some deterioration of the total acquired signal, compared to films of purely native transitional metal and its oxide. ${ }^{24,25,28,37}$ However, simplicity of preparation, utilization of low-cost materials, and preparation technologies provide great opportunity in the large-scale manufacturing of this type of sensors for adequate glucose detection levels, which requires distinguishing analyte levels from 100 to $10 \mathrm{mM}$ according to reports of the Diabetes Association. ${ }^{94}$

Glucose detection in blood, sweat, and urine requires high selectivity in sensing, due to the presence of other endogenous compounds such as urea, uric acid, acetic acid, and other sugars (sucrose, fructose), which constrain the functionality of the enzyme-free sensors. ${ }^{11}$ As is shown in Figure 6C, the fabricated electrodes showed no response to other analytes. However, $\mathrm{Cu}-\mathrm{MS}$ exhibited response to sucrose. The response attenuated to the baseline level after $\sim 1000 \mathrm{~s}$ and further did not show any significant contribution after multiple sucrose additions. However, sucrose is not present in the human body in the free form, and after digestion, converts to fructose and glucose, thus not directly contributing to the measurement of glucose levels. The activity to the sucrose occurs due to the oxidation of the micro- and nanostructured copper. ${ }^{80}$ The sucrose was hydrolyzed to fructose and glucose in the presence of an alkaline electrolyte, further promoting the generation of gluconic acid through a similar reaction chain, and is depicted in Figure $\mathrm{S} 10 \mathrm{~B} .{ }^{13,80}$ At the selected potential, only $\mathrm{Cu}-\mathrm{MS}$ indicated an increase in the amperometric signal, whereas $\mathrm{CuO}-\mathrm{U}$ was active only to glucose, and the reduction of the signal was observed via $\mathrm{CV}$ in Figure S9B.

The strong adhesion of microparticles to laser carbon substrate and the minor chemical variation of the amperometric response after multiple repetitions are depicted in Figure $6 \mathrm{D}$. The detachment of the nanoparticles slightly hinders further amperometric response. The nanoparticles show faster oxidation to the highest copper valence state, which is more brittle than an initial chemical modification. ${ }^{25}$ Notably, oxidation occurs at a significantly faster rate for $\mathrm{Cu}-$ MS. The revealing of the rough $\mathrm{CuO}-\mathrm{U}$ surface with reduced nanowire presence and underlying microparticles is still sufficient to provide a sufficient oxidation rate for amperometric signal within relatively close limits and show an $\sim 5 \%$ signal deterioration after each cycle. Despite EDX showing a significant change in the $\mathrm{Cu} / \mathrm{O}$ ratio, we speculate that the surface remains predominantly in the $\mathrm{CuO}$ phase due to the depth penetration of the electron beam within microns, a contribution from the core $\mathrm{Cu}_{2} \mathrm{O}$. During the amperometric test, only the soluble hydroxyl species were adsorbed on $\mathrm{CuO}$ $\mathrm{U}$; thus, the electrode could be reused after their removal by rinsing with DI water. ${ }^{11}$

A new generation of wearable smart devices (watches, bands, rings) has secured its position in the noninvasive, permanent monitoring of the heartbeat and pressure with reliable output, comparable to professional medicinal devices. Currently, the industry is expanding to cover direct real-time health risk monitoring of sweat, saliva, and blood. ${ }^{95}$ Inclusion of such sensors in the final device relies on their performance durability, selectivity of the detection, mechanical flexibility, and ease of manufacturing. However, the sensing area is currently constrained due to design requirements and the number of sensors is limited to the output voltage of the device for functional use throughout the day. ${ }^{95,96}$ New sensors can be included within movable parts, which require flexibility and bendability and are complemented with operation at a low power input $(\sim 100 \mathrm{~mW}) .{ }^{96}$ Thus, the selection of the material and engineering of the sensor must meet multiple parameters for successful commercial utilization. The glucose sensor reported here meets several of these requirements, such as selectivity of detection, operation during bending, and simplicity of the fabrication based on rapid manufacturing technologies. Further development in the engineering and packaging can provide improvement in the output currents by implementing conductive glue between the sensor substrate and the reading electrode, which can be fabricated by printing directly on the bendable films. Additionally, the complete sensor requires the realization of the detection electrode together with the counter electrode and the reference electrode in one system for real-time analyte monitoring, which can be easily implemented with printing and LIC technology. The sensor based on $\mathrm{CuO}-\mathrm{U}$ shows good repeatability after washing in DI water, and due to selectivity only to glucose, it is feasible to rinse with the running water. 


\section{CONCLUSIONS}

We have demonstrated the fabrication of $\mathrm{Cu}-\mathrm{MS}$ - and $\mathrm{CuO}-\mathrm{U}-$ based enzyme-free glucose sensors on a freestanding laser carbon film. They were fabricated on the initial substrate by the laser-induced carbonization from a Nomex sheet using optimized laser parameters, followed by the electroplating of copper for $10 \mathrm{~min}$. The electroplated copper was further annealed at $1000{ }^{\circ} \mathrm{C}$ in a nitrogen atmosphere to obtain $\mathrm{Cu}$ MS, which is caused by melting and wrapping of the initial copper sheets. The formation of $\mathrm{Cu}-\mathrm{MS}$ depended on the annealing temperature and duration of electroplating. Exposure to air at $450{ }^{\circ} \mathrm{C}$ during the cooling process resulted in the formation of urchin-like $\mathrm{CuO}$ seeded with nanowires, featuring a diameter starting from $15 \mathrm{~nm}$ and a length up to $5 \mu \mathrm{m}$. The performance of the composite electrodes toward the detection of glucose was investigated by cyclic voltammetry and real-time amperometric tests. Both electrode types exhibited amperometric activity in the presence of glucose with a superior sensitivity compared to other carbon-based glucose sensor materials. The sensitivities of the $\mathrm{Cu}-\mathrm{MS}$ and $\mathrm{CuO}-\mathrm{U}$ electrodes were 0.25 and $0.32 \mathrm{~mA} \mathrm{~cm}^{-2} \mathrm{mM}^{-1}$, respectively, within a linear range between $1 \mu \mathrm{M}$ and $3 \mathrm{mM}$. The limit of detection was estimated at 1.75 and $7.56 \mu \mathrm{M}$ for the $\mathrm{Cu}-\mathrm{MS}$ and $\mathrm{CuO}-\mathrm{U}$ electrodes, respectively, which are one of the lowest among carbon-based glucose sensors. Furthermore, the fabricated electrodes exhibited excellent selectivity toward glucose. However, the $\mathrm{Cu}-\mathrm{MS}$ electrode also exhibited some sensing activity in the presence of sucrose. The composite electrodes were also flexible and retained their sensing capabilities after multiple bending repetitions. The saturation sensitivity of the electrodes was determined at $10 \mathrm{mM}$, which is at the risk level for healthy humans from urine, sweat, and blood. These fabricated substrates are suitable for personalized, low-cost, point-of-care glucose monitoring and for the determination of sugar concentration in the food industry.

\section{ASSOCIATED CONTENT}

\section{SI Supporting Information}

The Supporting Information is available free of charge at https://pubs.acs.org/doi/10.1021/acsanm.1c03149.

$\mathrm{Cu}-\mathrm{MS}$ and $\mathrm{CuO}-\mathrm{U}$ evolution with variation in the duration of initial electroplating and annealing temperature, including evaluation of their sizes; assessment of the most suitable materials from sets prepared under different conditions; detailed study with TEM from selected $\mathrm{CuO}-\mathrm{U}$ and its substrate and additional characterization with Raman spectroscopy; XPS survey spectra of selected specimens and their compositional assessment; deconvolution from detailed XPS spectra; full cyclic voltammogram of the studied amperometric glucose biosensors in the presence of an electrolyte with added glucose or sucrose; and chemical formulas for the involved reactions (PDF)

\section{AUTHOR INFORMATION}

\section{Corresponding Author}

Jan G. Korvink - Institute of Microstructure Technology, Karlsruhe Institute of Technology, 76344 EggensteinLeopoldshafen, Germany; 이이이.org/0000-0003-43547295; Phone: +49 721 608-22740; Email: jan.korvink@ kit.edu

\section{Authors}

Emil R. Mamleyev - Institute of Microstructure Technology, Karlsruhe Institute of Technology, 76344 EggensteinLeopoldshafen, Germany; 이이.org/0000-0001-88465571

Peter G. Weidler - Institute of Functional Interfaces, Karlsruhe Institute of Technology, 76344 EggensteinLeopoldshafen, Germany

Alexei Nefedov - Institute of Functional Interfaces, Karlsruhe Institute of Technology, 76344 Eggenstein-Leopoldshafen,

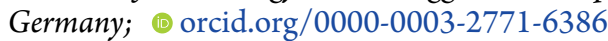

Dorothée Vinga Szabó - Institute for Applied Materials and Karlsruhe Nano Micro Facility, Karlsruhe Institute of Technology, 76344 Eggenstein-Leopoldshafen, Germany; Present Address: Institute of Nanotechnology, Karlsruhe Institute of Technology, Hermann-von-Helmholtz-Platz 1, 76344 Eggenstein-Leopoldshafen, Germany; 이이.org/ 0000-0002-5139-8771

Monsur Islam - Institute of Microstructure Technology, Karlsruhe Institute of Technology, 76344 EggensteinLeopoldshafen, Germany; 이이.org/0000-0002-48473996

Dario Mager - Institute of Microstructure Technology, Karlsruhe Institute of Technology, 76344 EggensteinLeopoldshafen, Germany

Complete contact information is available at: https://pubs.acs.org/10.1021/acsanm.1c03149

\section{Notes}

The authors declare no competing financial interest.

\section{ACKNOWLEDGMENTS}

E.R.M., M.I., D.M., and J.G.K. sincerely acknowledge financial support from the Deutsche Forschungsgemeinschaft (DFG, German Research Foundation) under Germany's Excellence Strategy via the Excellence Cluster 3D Matter Made to Order (EXC-2082/1-390761711). All authors express their gratitude to Microworks $\mathrm{GmbH}$ for sharing their electroplating facilities. E.R.M. sincerely acknowledges Stefan Heissler from the Institute of Functional Interfaces, Karlsruhe Institute of Technology, Hermann-von-Helmholtz-Platz 1, 76344 Eggenstein-Leopoldshafen, Germany, for performing Raman spectroscopy; Dr. Kerstin Länge for her help with the supply of analytes; and Vitor Vlnieska for his help in the interpretation and modeling of the electroplating kinetics, both from the Institute of Microstructure Technology, Karlsruhe Institute of Technology, Eggenstein-Leopoldshafen, Germany. All authors acknowledge the excellent support by the Karlsruhe Institute of Technology, especially for maintaining safety during the COVID-19 pandemic.

\section{REFERENCES}

(1) Siscovick, D. S.; Sotoodehnia, N.; Rea, T. D.; Raghunathan, T. E.; Jouven, X.; Lemaitre, R. N. Type 2 diabetes mellitus and the risk of sudden cardiac arrest in the community. Rev. Endocr. Metab. Disord. 2010, 11, 53-59.

(2) Parfrey, P. S.; Griffiths, S. M.; Barrett, B. J.; Paul, M. D.; Genge, M.; Withers, J.; Farid, N.; McManamon, P. J. Contrast materialinduced renal failure in patients with diabetes mellitus, renal insufficiency, or both. N. Engl. J. Med. 1989, 320, 143-149.

(3) Stefánsson, E.; Bek, T.; Porta, M.; Larsen, N.; Kristinsson, J. K.; Agardh, E. Screening and prevention of diabetic blindness. Acta Ophthalmol. Scand. 2000, 78, 374-385. 
(4) Kameyamai, M.; Fushmi, H.; Udaka, F. Diabetes mellitus and cerebral vascular disease. Diabetes Res. Clin. Pract. 1994, 24, S205S208.

(5) Saeedi, P.; Petersohn, I.; Salpea, P.; Malanda, B.; Karuranga, S.; Unwin, N.; Colagiuri, S.; Guariguata, L.; Motala, A. A.; Ogurtsova, K.; et al. Global and regional diabetes prevalence estimates for 2019 and projections for 2030 and 2045: Results from the International Diabetes Federation Diabetes Atlas. Diabetes Res. Clin. Pract. 2019, 157, No. 107843.

(6) Malanda, U. L.; Welschen, L. M.; Riphagen, I. I.; Dekker, J. M.; Nijpels, G.; Bot, S. D. Self-monitoring of blood glucose in patients with type 2 diabetes mellitus who are not using insulin. Cochrane Database Syst. Rev. 2012, No. CD005060.

(7) Tehrani, F.; Bavarian, B. Facile and scalable disposable sensor based on laser engraved graphene for electrochemical detection of glucose. Sci. Rep. 2016, 6, No. 27975.

(8) Yoon, H.; Nah, J.; Kim, H.; Ko, S.; Sharifuzzaman, M.; Barman, S. C.; Xuan, X.; Kim, J.; Park, J. Y. A chemically modified laserinduced porous graphene based flexible and ultrasensitive electrochemical biosensor for sweat glucose detection. Sens. Actuators, B 2020, 311, No. 127866.

(9) Clark, L. C., Jr.; Lyons, C. Electrode systems for continuous monitoring in cardiovascular surgery. Ann. N. Y. Acad. Sci. 1962, 102, $29-45$.

(10) Zhu, T.; Wang, X.; Chang, W.; Zhang, Y.; Maruyama, T.; Luo, L.; Zhao, X. Green fabrication of $\mathrm{Cu} / \mathrm{rGO}$ decorated SWCNT buckypaper as a flexible electrode for glucose detection. Mater. Sci. Eng., C 2021, 120, No. 111757.

(11) Zhang, Y.; Su, L.; Manuzzi, D.; de los Monteros, H. V. E.; Jia, W.; Huo, D.; Hou, C.; Lei, Y. Ultrasensitive and selective nonenzymatic glucose detection using copper nanowires. Biosens. Bioelectron. 2012, 31, 426-432.

(12) Wong, C. M.; Wong, K. H.; Chen, X. D. Glucose oxidase: natural occurrence, function, properties and industrial applications. Appl. Microbiol. Biotechnol. 2008, 78, 927-938.

(13) Nordin, N.; Bordonali, L.; Davoodi, H.; Ratnawati, N. D.; Gygli, G.; Korvink, J. G.; Badilita, V.; MacKinnon, N. Real-time NMR monitoring of spatially segregated enzymatic reactions in multilayered hydrogel assemblies. Angew. Chem. 2021, 19325.

(14) Park, S.; Chung, T. D.; Kim, H. C. Nonenzymatic glucose detection using mesoporous platinum. Anal. Chem. 2003, 75, 30463049.

(15) Jena, B. K.; Raj, C. R. Enzyme-free amperometric sensing of glucose by using gold nanoparticles. Chem.-Eur. J. 2006, 12, 27022708

(16) Meng, L.; Jin, J.; Yang, G.; Lu, T.; Zhang, H.; Cai, C. Nonenzymatic electrochemical detection of glucose based on palladium- single-walled carbon nanotube hybrid nanostructures. Anal. Chem. 2009, 81, 7271-7280.

(17) Waqas, M.; Lan, J.; Zhang, X.; Fan, Y.; Zhang, P.; Liu, C.; Jiang, Z.; Wang, X.; Zeng, J.; Chen, W. Fabrication of Non-enzymatic Electrochemical Glucose Sensor Based on Pd- Mn Alloy Nanoparticles Supported on Reduced Graphene Oxide. Electroanalysis 2020, 32, 1226-1236.

(18) Toghill, K. E.; Xiao, L.; Phillips, M. A.; Compton, R. G. The non-enzymatic determination of glucose using an electrolytically fabricated nickel microparticle modified boron-doped diamond electrode or nickel foil electrode. Sens. Actuators, B 2010, 147, 642-652.

(19) Bai, X.; Chen, W.; Song, Y.; Zhang, J.; Ge, R.; Wei, W.; Jiao, Z.; Sun, Y. Nickel-copper oxide nanowires for highly sensitive sensing of glucose. Appl. Surf. Sci. 2017, 420, 927-934.

(20) Zhang, Y.; Li, N.; Xiang, Y.; Wang, D.; Zhang, P.; Wang, Y.; Lu, $\mathrm{S}$; $\mathrm{Xu}, \mathrm{R}$; Zhao, J. A flexible non-enzymatic glucose sensor based on copper nanoparticles anchored on laser-induced graphene. Carbon 2020, 156, 506-513.

(21) Guo, C.; Wang, Y.; Zhao, Y.; Xu, C. Non-enzymatic glucose sensor based on three dimensional nickel oxide for enhanced sensitivity. Anal. Methods 2013, 5, 1644-1647.
(22) Wu, L.-N.; Zhong, J.-P.; Waqas, M.; Jiang, Z.; Fan, Y.-J.; Sun, Y.; Li, J.; Chen, W. Controllable synthesis of six corner star-like Cu2O/PEDOT-MWCNT composites and their performance toward electrochemical glucose sensing. Electrochim. Acta 2019, 318, 837846.

(23) Waqas, M.; Wu, L.; Tang, H.; Liu, C.; Fan, Y.; Jiang, Z.; Wang, $\mathrm{X}$; Zhong, J.; Chen, W. Cu2O microspheres supported on sulfurdoped carbon nanotubes for glucose sensing. ACS Appl. Nano Mater. 2020, 3, 4788-4798.

(24) Luo, L.; Zhu, L.; Wang, Z. Nonenzymatic amperometric determination of glucose by $\mathrm{CuO}$ nanocubes-graphene nanocomposite modified electrode. Bioelectrochemistry 2012, 88, 156-163. (25) Fan, Z.; Liu, B.; Liu, X.; Li, Z.; Wang, H.; Yang, S.; Wang, J. A flexible and disposable hybrid electrode based on $\mathrm{Cu}$ nanowires modified graphene transparent electrode for non-enzymatic glucose sensor. Electrochim. Acta 2013, 109, 602-608.

(26) Yang, J.; Jiang, L. C.; Zhang, W. D.; Gunasekaran, S. A highly sensitive non-enzymatic glucose sensor based on a simple two-step electrodeposition of cupric oxide $(\mathrm{CuO})$ nanoparticles onto multiwalled carbon nanotube arrays. Talanta 2010, 82, 25-33.

(27) Bao, J.; Hou, C.; Zhang, Y.; Li, Q.; Huo, D.; Yang, M.; Luo, X. A Non-Enzymatic Glucose Sensor based on Copper Oxide Nanowires-Single Wall Carbon Nanotubes. J. Electrochem. Soc. 2015, 162, B47-B51.

(28) Reitz, E.; Jia, W.; Gentile, M.; Wang, Y.; Lei, Y. CuO Nanospheres Based Nonenzymatic Glucose Sensor. Electroanalysis 2008, 20, 2482-2486.

(29) Meng, Z.; Sheng, Q.; Zheng, J. A sensitive non-enzymatic glucose sensor in alkaline media based on $\mathrm{Cu} / \mathrm{MnO} 2$-modified glassy carbon electrode. J. Iran. Chem. Soc. 2012, 9, 1007-1014.

(30) Wang, L.; Lu, X.; Wen, C.; Xie, Y.; Miao, L.; Chen, S.; Li, H.; $\mathrm{Li}$, P.; Song, Y. One-step synthesis of Pt-NiO nanoplate array/reduced graphene oxide nanocomposites for nonenzymatic glucose sensing. $J$. Mater. Chem. A 2015, 3, 608-616.

(31) Liu, Y.; Wang, M.; Zhao, F.; Xu, Z.; Dong, S. The direct electron transfer of glucose oxidase and glucose biosensor based on carbon nanotubes/chitosan matrix. Biosens. Bioelectron. 2005, 21, 984-988.

(32) He, G.; Wang, L. One-step preparation of ultra-thin copper oxide nanowire arrays/copper wire electrode for non-enzymatic glucose sensor. Ionics 2018, 24, 3167-3175.

(33) Lu, W.; Sun, Y.; Dai, H.; Ni, P.; Jiang, S.; Wang, Y.; Li, Z.; Li, Z. $\mathrm{CuO}$ nanothorn arrays on three-dimensional copper foam as an ultrahighly sensitive and efficient nonenzymatic glucose sensor. RSC Adv. 2016, 6, 16474-16480.

(34) Sun, S.; Zhang, X.; Sun, Y.; Yang, S.; Song, X.; Yang, Z. Facile water-assisted synthesis of cupric oxide nanourchins and their application as nonenzymatic glucose biosensor. ACS Appl. Mater. Interfaces 2013, 5, 4429-4437.

(35) Li, J.-Y.; Xiong, S.; Pan, J.; Qian, Y. Hydrothermal Synthesis and Electrochemical Properties of Urchin-Like Core-Shell Copper Oxide Nanostructures. J. Phys. Chem. C 2010, 114, 9645-9650.

(36) Wang, Z.; Xiao, Y.; Cui, X.; Cheng, P.; Wang, B.; Gao, Y.; Li, X.; Yang, T.; Zhang, T.; Lu, G. Humidity-Sensing Properties of Urchinlike $\mathrm{CuO}$ Nanostructures Modified by Reduced Graphene Oxide. ACS Appl. Mater. Interfaces 2014, 6, 3888-3895.

(37) Sedighi, A.; Montazer, M.; Mazinani, S. Synthesis of wearable and flexible NiP0.1-SnOx/PANI/CuO/cotton towards a nonenzymatic glucose sensor. Biosens. Bioelectron. 2019, 135, 192-199.

(38) Zhang, X.; Turcheniuk, K.; Zusmann, B.; Benson, J.; Nelson, S.; Luo, S.; Magasinski, A.; Yushin, G. Synthesis of copper oxide nanowires and nanoporous copper via environmentally friendly transformation of bulk copper-calcium alloys. Chem. Commun. 2018, $54,5446-5449$.

(39) Srinivasan, R.; Hall, R. R.; Wilson, W. D.; Loehle, W. D.; Allbee, D. C. Formation of a Porous, Patternable, Electrically Conducting Carbon Network by the Ultraviolet Laser Irradiation of the Polyimide PMDA-ODA (Kapton). Chem. Mater. 1994, 6, 888889 . 
(40) Lin, J.; Peng, Z.; Liu, Y.; Ruiz-Zepeda, F.; Ye, R.; Samuel, E. L. G.; Yacaman, M. J.; Yakobson, B. I.; Tour, J. M. Laser-induced porous graphene films from commercial polymers. Nat. Commun. 2014, 5, No. 5714.

(41) Dyer, P. E.; Pervolaraki, M.; Lippert, T. Experimental studies and thermal modelling of 1064- And 532-nm Nd:YVO 4 micro-laser ablation of polyimide. Appl. Phys. A: Mater. Sci. Process. 2005, 80, 529-536.

(42) Srinivasan, R.; Braren, B.; Dreyfus, R. W. Ultraviolet laser ablation of polyimide films. J. Appl. Phys. 1987, 61, 372-376.

(43) Chyan, Y.; Ye, R.; Li, Y.; Singh, S. P.; Arnusch, C. J.; Tour, J. M. Laser-Induced Graphene by Multiple Lasing: Toward Electronics on Cloth, Paper, and Food. ACS Nano 2018, 12, 2176-2183.

(44) Mamleyev, E. R.; Falk, F.; Weidler, P. G.; Heissler, S.; Wadhwa, S.; Nassar, O.; Shyam Kumar, C. N.; Kübel, C.; Wöll, C.; Islam, M.; Mager, D.; Korvink, J. G. Polyaramid-Based Flexible Antibacterial Coatings Fabricated Using Laser-Induced Carbonization and Copper Electroplating. ACS Appl. Mater. Interfaces 2020, 12, 53193-53205.

(45) Kaidarova, A.; Marengo, M.; Marinaro, G.; Geraldi, N.; Duarte, C. M.; Kosel, J. Flexible and Biofouling Independent Salinity Sensor. Adv. Mater. Interfaces 2018, 5, No. 1801110.

(46) Cardoso, A. R.; Marques, A. C.; Santos, L.; Carvalho, A. F.; Costa, F. M.; Martins, R.; Sales, M. G. F.; Fortunato, E. Molecularlyimprinted chloramphenicol sensor with laser-induced graphene electrodes. Biosens. Bioelectron. 2019, 124-125, 167-175.

(47) Nayak, P.; Kurra, N.; Xia, C.; Alshareef, H. N. Highly Efficient Laser Scribed Graphene Electrodes for On-Chip Electrochemical Sensing Applications. Adv. Electron. Mater. 2016, 2, No. 1600185.

(48) Mamleyev, E. R.; Heissler, S.; Nefedov, A.; Weidler, P. G.; Nordin, N.; Kudryashov, V. V.; Länge, K.; MacKinnon, N.; Sharma, S. Laser-induced hierarchical carbon patterns on polyimide substrates for flexible urea sensors. npj Flexible Electron. 2019, 3, No. 2.

(49) Xu, G.; Jarjes, Z. A.; Desprez, V.; Kilmartin, P. A.; TravasSejdic, J. Sensitive, selective, disposable electrochemical dopamine sensor based on PEDOT-modified laser scribed graphene. Biosens. Bioelectron. 2018, 107, 184-191.

(50) Xu, G.; Jarjes, Z. A.; Desprez, V.; Kilmartin, P. A.; TravasSejdic, J. Sensitive, selective, disposable electrochemical dopamine sensor based on PEDOT-modified laser scribed graphene. Biosens. Bioelectron. 2018, 107, 184-191.

(51) Zanoni, J.; Moura, J. P.; Santos, N. F.; Carvalho, A. F.; Fernandes, A. J.; Monteiro, T.; Costa, F. M.; Pereira, S. O.; Rodrigues, J. Dual Transduction of $\mathrm{H} 2 \mathrm{O} 2$ Detection Using $\mathrm{ZnO} /$ Laser-Induced Graphene Composites. Chemosensors 2021, 9, No. 102.

(52) Fenzl, C.; Nayak, P.; Hirsch, T.; Wolfbeis, O. S.; Alshareef, H. N.; Baeumner, A. J. Laser-scribed graphene electrodes for aptamerbased biosensing. ACS Sens. 2017, 2, 616-620.

(53) Kim, G.-J.; Kim, T.; Pak, J. Development of Flexible Glucose Measurement Sensor Based on Copper Nanocubes Electroplated Laser Induced Graphene Electrode. Trans. Korean Inst. Electr. Eng. 2018, 67, 413-418.

(54) Zhang, K.; Rossi, C.; Tenailleau, C.; Alphonse, P.; ChaneChing, J.-Y. Synthesis of large-area and aligned copper oxide nanowires from copper thin film on silicon substrate. Nanotechnology 2007, 18, No. 275607

(55) Park, Y.-W.; Seong, N.-J.; Jung, H.-J.; Chanda, A.; Yoon, S.-G. Growth Mechanism of the Copper Oxide Nanowires from Copper Thin Films Deposited on CuO-Buffered Silicon Substrate. J. Electrochem. Soc. 2010, 157, K119.

(56) Rietveld, H. M. A profile refinement method for nuclear and magnetic structures. J. Appl. Crystallogr. 1969, 2, 65-71.

(57) Gammer, C.; Mangler, C.; Rentenberger, C.; Karnthaler, H. Quantitative local profile analysis of nanomaterials by electron diffraction. Scr. Mater. 2010, 63, 312-315.

(58) Zhu, W.; Wang, J.; Zhang, W.; Hu, N.; Wang, J.; Huang, L.; Wang, R.; Suo, Y.; Wang, J. Monolithic copper selenide submicron particulate film/copper foam anode catalyst for ultrasensitive electrochemical glucose sensing in human blood serum. J. Mater. Chem. B 2018, 6, 718-724.
(59) Warren, B. E. X-ray diffraction in random layer lattices. Phys. Rev. 1941, 59, 693-698.

(60) Franklin, R. E. The interpretation of diffuse X-ray diagrams of carbon. Acta Crystallogr. 1950, 3, 107-121.

(61) Meghana, S.; Kabra, P.; Chakraborty, S.; Padmavathy, N. Understanding the pathway of antibacterial activity of copper oxide nanoparticles. RSC Adv. 2015, 5, 12293-12299.

(62) Ferrari, A. C.; Basko, D. M. Raman spectroscopy as a versatile tool for studying the properties of graphene. Nat. Nanotechnol. 2013, $8,235$.

(63) Malard, L. M.; Pimenta, M. A.; Dresselhaus, G.; Dresselhaus, M. S. Raman spectroscopy in graphene. Phys. Rep. 2009, 473, 51-87. (64) Xu, J. F.; Ji, W.; Shen, Z. X.; Li, W. S.; Tang, S. H.; Ye, X. R.; Jia, D. Z.; Xin, X. Q. Raman spectra of $\mathrm{CuO}$ nanocrystals. J. Raman Spectrosc. 1999, 30, 413-415.

(65) Akgul, F. A.; Akgul, G.; Yildirim, N.; Unalan, H. E.; Turan, R. Influence of thermal annealing on microstructural, morphological, optical properties and surface electronic structure of copper oxide thin films. Mater. Chem. Phys. 2014, 147, 987-995.

(66) Zeng, D.; Yung, K.; Xie, C. XPS investigation of the chemical characteristics of Kapton films ablated by a pulsed TEA CO2 laser. Surf. Coat. Technol. 2002, 153, 210-216.

(67) Kaciulis, S. Spectroscopy of carbon: From diamond to nitride films. Surf. Interface Anal. 2012, 44, 1155-1161.

(68) Hu, C. Z.; Andrade, J. D. Pyrolyzed, conducting kapton polyimide: An electrically conducting material. J. Appl. Polym. Sci. 1985, 30, 4409-4415.

(69) Jansen, R. J. J.; van Bekkum, H. XPS of nitrogen-containing functional groups on activated carbon. Carbon 1995, 1021.

(70) McCafferty, E.; Wightman, J. Determination of the concentration of surface hydroxyl groups on metal oxide films by a quantitative XPS method. Surf. Interface Anal. 1998, 26, 549-564.

(71) Shchukarev, A.; Korolkov, D. XPS study of group IA carbonates. Open Chem. 2004, 2, 347-362.

(72) Melke, J.; Peter, B.; Habereder, A.; Ziegler, J.; Fasel, C.; Nefedov, A.; Sezen, H.; Wöll, C.; Ehrenberg, H.; Roth, C. MetalSupport Interactions of Platinum Nanoparticles Decorated N-Doped Carbon Nanofibers for the Oxygen Reduction Reaction. ACS Appl. Mater. Interfaces 2016, 8, 82-90.

(73) Chen, Y.; Xie, B.; Ren, Y.; Yu, M.; Qu, Y.; Xie, T.; Zhang, Y.; $\mathrm{Wu}, \mathrm{Y}$. Designed nitrogen doping of few-layer graphene functionalized by selective oxygenic groups. Nanoscale Res. Lett. 2014, 9, No. 646.

(74) Biesinger, M. C.; Payne, B. P.; Grosvenor, A. P.; Lau, L. W.; Gerson, A. R.; Smart, R. S. Resolving surface chemical states in XPS analysis of first row transition metals, oxides and hydroxides: $\mathrm{Cr}, \mathrm{Mn}$, Fe, Co and Ni. Appl. Surf. Sci. 2011, 257, 2717-2730.

(75) Biesinger, M. C. Advanced analysis of copper X-ray photoelectron spectra. Surf. Interface Anal. 2017, 49, 1325-1334.

(76) Marioli, J. M.; Kuwana, T. Electrochemical characterization of carbohydrate oxidation at copper electrodes. Electrochim. Acta 1992, 37, 1187-1197.

(77) Guo, M. M.; Xia, Y.; Huang, W.; Li, Z. Electrochemical fabrication of stalactite-like copper micropillar arrays via surface rebuilding for ultrasensitive nonenzymatic sensing of glucose. Electrochim. Acta 2015, 151, 340-346.

(78) Hou, L.; Zhao, H.; Bi, S.; Zhu, L.; Xu, Y.; Lu, Y. Ultrasensitive and highly flexible nonenzymatic glucose biosensor based on laserscribed carbon paper substrate. Appl. Surf. Sci. 2019, 465, 320-331.

(79) Kissinger, P. T.; Heineman, W. R. Cyclic voltammetry. J. Chem. Educ. 1983, 60, 702 .

(80) Feng, H.; Huang, Z.; Lou, X.; Li, J.; Hui, G. Study of a Sucrose Sensor by Functional $\mathrm{Cu}$ Foam Material and Its Applications in Commercial Beverages. Food Anal. Methods 2017, 10, 407-418.

(81) Brannon, J. H.; Lankard, J. R.; Baise, A. I.; Burns, F.; Kaufman, J. Excimer laser etching of polyimide. J. Appl. Phys. 1985, 58, 20362043

(82) Doyle, D. J.; Kokosa, J. M. The laser cutting of kevlar: A study of the chemical by-products. Mater. Manuf. Processes 1990, 5, 609615 . 
(83) Sharma, S.; Kumar, C. S.; Korvink, J. G.; Kübel, C. Evolution of glassy carbon microstructure: in situ transmission electron microscopy of the pyrolysis process. Sci. Rep. 2018, 8, No. 16282.

(84) Ortelli, E. E.; Geiger, F.; Lippert, T.; Wei, J.; Wokaun, A. UVLaser-Induced Decomposition of Kapton Studied by Infrared Spectroscopy. Macromolecules 2000, 33, 5090-5097.

(85) Cui, C.; Gao, Y.; Li, J.; Yang, C.; Liu, M.; Jin, H.; Xia, Z.; Dai, L.; Lei, Y.; Wang, J.; Wang, S. Origins of Boosted Charge Storage on Heteroatom-Doped Carbons. Angew. Chem. 2020, 132, 8002-8007.

(86) Mattevi, C.; Kim, H.; Chhowalla, M. A review of chemical vapour deposition of graphene on copper. J. Mater. Chem. 2011, 21, $3324-3334$

(87) Gromov, D. G.; Gavrilov, S. A.; Redichev, E. N.; Ammosov, R. $\mathrm{M}$. Kinetics of the melting-dispersion process in copper thin films. Phys. Solid State 2007, 49, 178-184.

(88) Gromov, D. G.; Gavrilov, S. A. Thermodynamics-Physical Chemistry of Aqueous Systems; IntechOpen: Rijeka, Croatia, 2011; pp 157-190.

(89) Han, Y.; Lai, K. C.; Lii-Rosales, A.; Tringides, M. C.; Evans, J. W.; Thiel, P. A. Surface energies, adhesion energies, and exfoliation energies relevant to copper-graphene and copper-graphite systems. Surf. Sci. 2019, 685, 48-58.

(90) de Gennes, P. G. Wetting: statics and dynamics. Rev. Mod. Phys. 1985, 57, 827-863.

(91) Ferrari, A. C.; Kleinsorge, B.; Morrison, N. A.; Hart, A.; Stolojan, V.; Robertson, J. Stress reduction and bond stability during thermal annealing of tetrahedral amorphous carbon. J. Appl. Phys. 1999, 85, 7191-7197.

(92) Jiang, X.; Herricks, T.; Xia, Y. CuO Nanowires Can Be Synthesized by Heating Copper Substrates in Air. Nano Lett. 2002, 2, 1333-1338.

(93) Pfefferkorn, G. Elektronenmikroskopische Untersuchungen über den Oxydationsvorgang von Metallen. Naturwissenschaften 1953, 40, 551-552.

(94) Moyer, J.; Wilson, D.; Finkelshtein, I.; Wong, B.; Potts, R. Correlation between sweat glucose and blood glucose in subjects with diabetes. Diabetes Technol. Ther. 2012, 14, 398-402.

(95) Matzeu, G.; Florea, L.; Diamond, D. Advances in wearable chemical sensor design for monitoring biological fluids. Sens. Actuators, B 2015, 211, 403-418.

(96) Maurer, U.; Rowe, A.; Smailagic, A.; Siewiorek, D. P. In eWatch: A Wearable Sensor and Notification Platform, International Workshop on Wearable and Implantable Body Sensor Networks (BSN'06), 2006; pp 1-4.

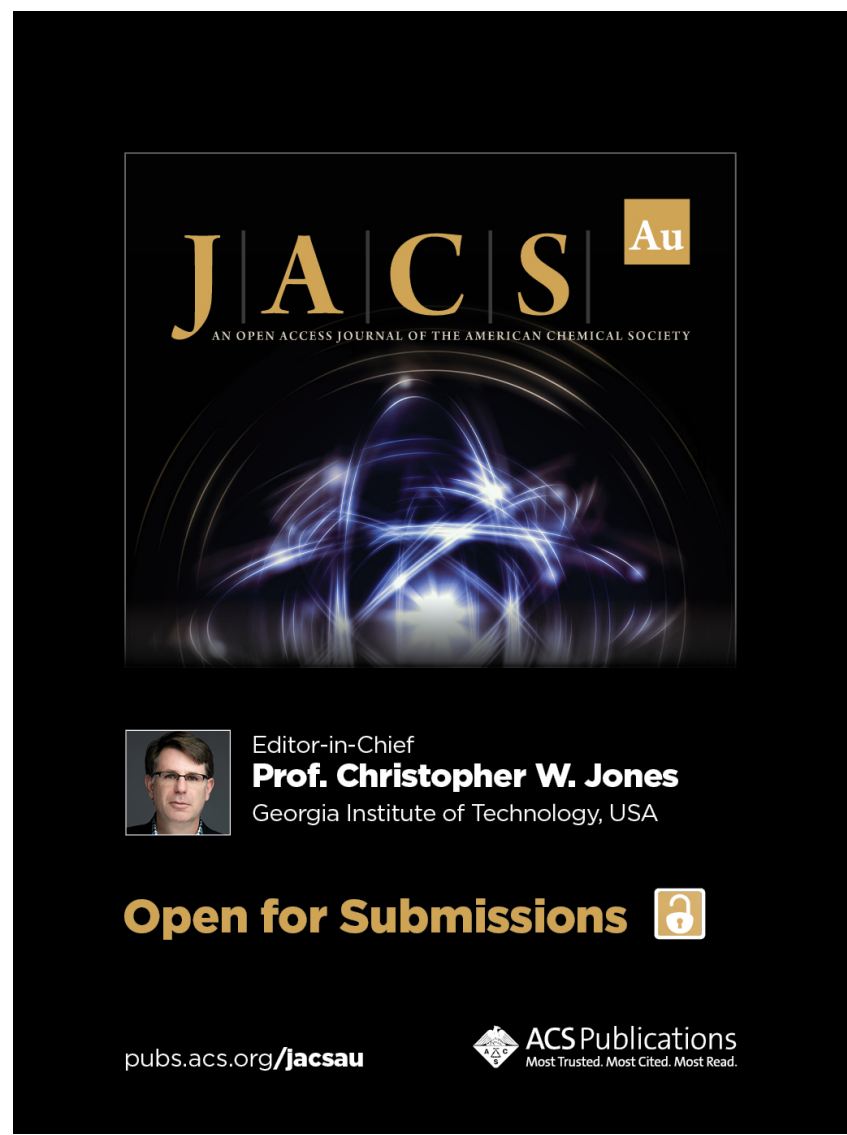

